\title{
Impact of communication time delays on combined LFC and AVR of a multi-area hybrid system with IPFC-RFBs coordinated control strategy
}

\author{
C H. Naga Sai Kalyan ${ }^{1 *}$ and G. Sambasiva Rao ${ }^{2}$
}

\begin{abstract}
In this paper, the impact of communication time delays (CTDs) on combined load frequency control (LFC) and automatic voltage regulation (AVR) of a multi-area system with hybrid generation units is addressed. Investigation reveals that CTDs have significant effect on system performance. A classical PID controller is employed as a secondary regulator and its parametric gains are optimized with a differential evolution - artificial electric field algorithm (DE-AEFA). The superior performance of the presented algorithm is established by comparing with various optimization algorithms reported in the literature. The investigation is further extended to integration of redox flow batteries (RFBs) and interline power flow controller (IPFC) with tie-lines. Analysis reveals that IPFC and RFBs coordinated control enhances system dynamic performance. Finally, the robustness of the proposed control methodology is validated by sensitivity analysis during wide variations of system parameters and load.
\end{abstract}

Keywords: Combined LFC-AVR, Communication time delays (CTDs), IPFC-RFBs strategy, DE-AEFA algorithm

\section{Introduction}

A modern power system incorporates a variety of power generation units interconnected together to provide high quality power to meet varying load demand. These generation units are usually grouped to form coherent groups or control areas, while all generators in control areas must run in synchrony. Each control area is intended to be associated with other control areas through tie-lines, where power exchanges between control areas take place. As the system load is never constant, maintaining system stability, which depends on maintaining both frequency and system terminal voltage, is the most challenging task. The control over frequency can be achieved by minimizing active power mismatch between demand and generation through regulating the generator speed governor via LFC. The system terminal

\footnotetext{
*Correspondence: kalyanchallapalli@gmail.com

${ }^{1}$ EEE Department, Acharya Nagarjuna University, Guntur, A.P., India Full list of author information is available at the end of the article
}

voltage is regulated by generator AVR through changing the generator field excitation current.

LFC of a thermal power system was first examined in [1] and then was extended to multi-area interconnected systems with multi-type generation units. Various investigations on different test systems have been carried out. References [2, 3] analyze multi-area thermal plant possessing non-reheat turbine structure with and without considering GRCs and GDB nonlinearity, respectively. Two areas of equal generation capacity with hydrothermal units of reheat turbines are considered for investigation in [4-6] but system nonlinearity is not considered. In [5], the investigation is extended to incorporate wind, solar photovoltaics (PV), aqua-electrolyzes and fuel cells. References [7, 8] consider the incorporation of power generation through gas and nuclear plants in conventional hydrothermal systems. However, in [1-7], only the LFC problem is investigated while the AVR coupling is not considered. 
Many studies have been carried out on either LFC or AVR, but investigations into their combined effect have been limited. References $[9,10]$ analyze the combined power system model, but they limit to a single area. A two-area combined model is investigated in [11], but the system nonlinearity is not considered. In [12], a combined three-area interconnected system with multi-type generation units considering GRC and GDB is studied, but CTDs are not considered. Most work on AGC and on combined LFC and AVR of interconnected systems mainly concentrate on the nonlinearities of GRC and GDB and give lower priority to the consideration of CTDs. This motivates the examination of a two-area system with hybrid power generation sources in the presence of CTDs with combined effect, as the effect of CTDs on a multi-area LFC and AVR combined model has not been reported.

In both LFC and AVR loops, design of secondary regulator plays a critical role in damping out the frequency and terminal voltage deviations under varying load demand. Conventional controllers such as I/PI $[8,11] /$ PID $[2,3,13] /$ PID with filter (PIDN) and higher order degree of freedom (DOF) [12] controllers have been reported. Intelligence-based controllers have also been implemented such as fuzzy PI/ fuzzy PID $[6,14,15]$, and FAMCON tool box based controllers such as fractional order (FO)PI/ FOPID controllers [7, 16]. However, the performance of the controllers relies heavily on optimum gain values, which can be obtained by employing soft computing techniques. Algorithms such as particle swarm optimization (PSO) [17], grey wolf optimization (GWO) [2], improved GWO (IGWO) [15], teachinglearning based optimization (TLBO) [16], artificial bee colony optimization (ABC) [18], backtracking search algorithm (BSA) [19], imperialist competitive algorithm (ICA) [20], lightning search algorithm (LSA) [12], simulated annealing (SA) [11], flower pollination algorithm (FPA) [13], hybrid firefly- pattern search (hFA-PS) [21], HGA-PSO [3] etc. have been employed to obtain controller optimum gains. However, many of these optimization algorithms have disadvantages such as slow convergence, being easily trapped into local minima, and insufficiency in asserting average equilibrium between exploitation and exploration.

The problem considered in this work is a more realistic complex problem. Small variations in algorithm parameters may lead to large disturbances in system dynamic response. Thus, a robust and sovereign optimization algorithm is needed. To address the challenges, a new strategy of DEAEFA is presented to obtain parameters of the secondary controller in LFC and AVR loops. The superiority of the DEAEFA algorithm is validated on benchmark standard test functions that will be detailed in Section 4.
The objectives of this paper are:

a) To design a multi-area combined LFC and AVR model consists of hybrid generation sources considering GRCs and CTDs.

b) To solve the complex realistic problem, a novel DEAEFA algorithm is presented to obtain the optimum parametric gains of the secondary controller.

c) To test the effectiveness of the proposed algorithm, its performance is compared with other optimization methods tested on widely used interconnected systems reported in the literature.

d) To examine the impact of AVR and CTDs, system dynamic responses are analyzed with and without considering AVR and CTDs.

e) To further examine the coordinated performance of IPFC and RFBs with the proposed DE-AEFA optimized PID for the realistic system.

f) To manifest the robustness of the proposed coordinated control approach using sensitivity analysis.

\section{Power system models}

\subsection{Test systems under investigation}

Despite the nonlinear nature of realistic power systems, extensive work on linear models in LFC domain has been reported. In addition, the nonlinearities of the system with such as CTDs, GRC and GDB have been investigated. Incorporation of such nonlinearities affects system dynamic performance. Hence, study on LFC domain should be carried out to investigate the impact of nonlinearities. Various models of interconnected systems have been considered for investigation by many researchers.

Three test systems are considered in this paper including a two-area system with equal generation capacity of thermal power plant with non-reheat turbines (test system-1) in Fig. 1, a two-area system of hydrothermal generation units with reheat turbines (test system-2) in Fig. 2, and a two-area LFC and AVR combined model system with hybrid generation sources considering CTDs and GRC (test system-3) in Fig. 3. Test systems 1 and 2 are analyzed to regulate area frequency and deviations in power exchange among control areas with the presented DE-AEFA-based PID and the responses are compared with those of other reported control strategies. On test system-3, investigation is carried out to analyze the combined LFC and AVR effect on simultaneous extenuation of deviations of system frequency, voltage and power exchange through a tie-line. The test system models depicted in Fig. 1 [2,17] and Fig. $2[18]$ are extensively reported on in the literature, whereas the power system depicted in Fig. 3 is examined here. 


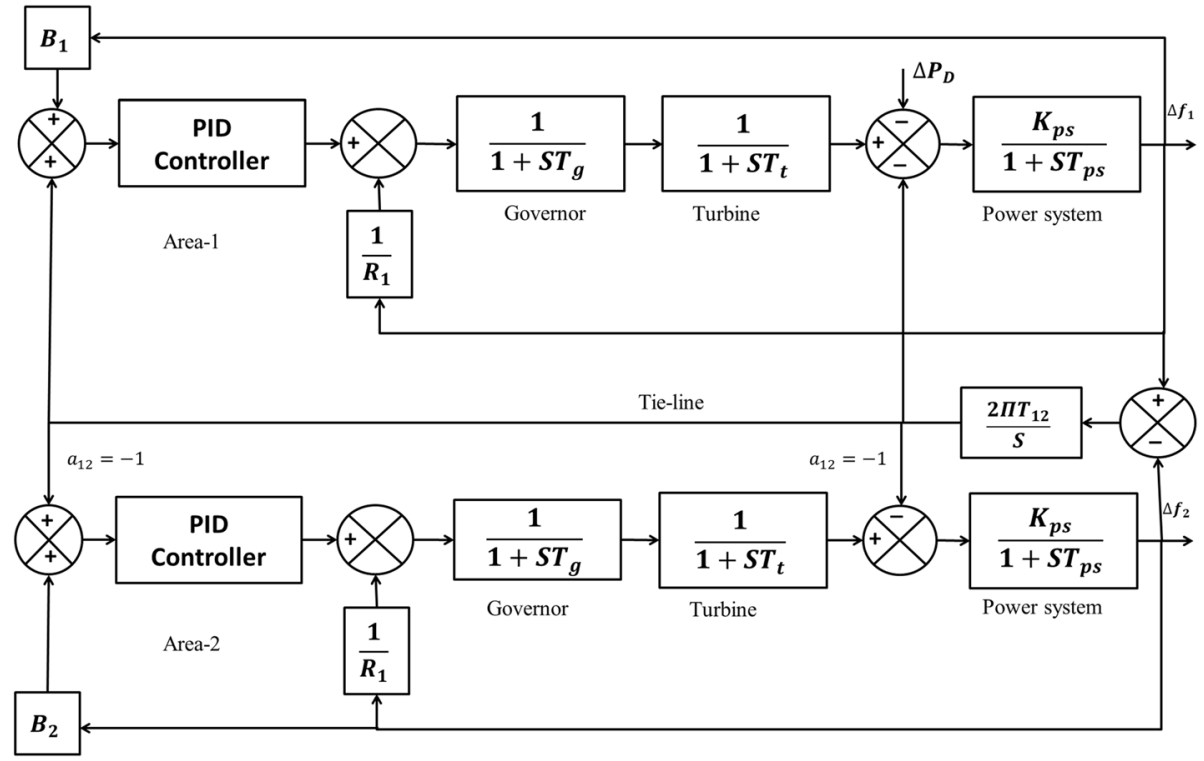

Fig. 1 Two area thermal power plant with non-reheat turbine structure (test system-1)

\subsection{Modeling of AVR coupling with LFC}

The system frequency and voltage can be controlled simultaneously through a combined LFC and AVR model. AVR is coupled to LFC through cross coupling coefficients K1, K2, $\mathrm{K} 3$ and K4 shown in Fig. 4. In this combined model, frequency is regulated by regulating active power mismatch among generations and demands through the LFC loop while maintaining the system terminal voltage is taken care of by the AVR loop. The AVR loop consists of an amplifier, an exciter, a sensor and a generator field unit. The sensor unit continuously monitors the terminal voltage and generates an error signal which is used to change the generator field excitation after amplification. The active power mismatch among demands and generations results in frequency fluctuation. The terminal voltage is also affected by the variation in frequency as the emf of the generator stator winding is proportional to frequency. These controlling measures in the AVR loop affect generator armature terminal EMF $E$ which subsequently influences real power generation as [22]:

$$
\mathrm{P}_{\mathrm{e}}=\frac{|\mathrm{V}|\left|\mathrm{E}^{\prime}\right|^{\prime}}{\mathrm{X}_{\mathrm{S}}} \operatorname{Sin}(\delta)
$$

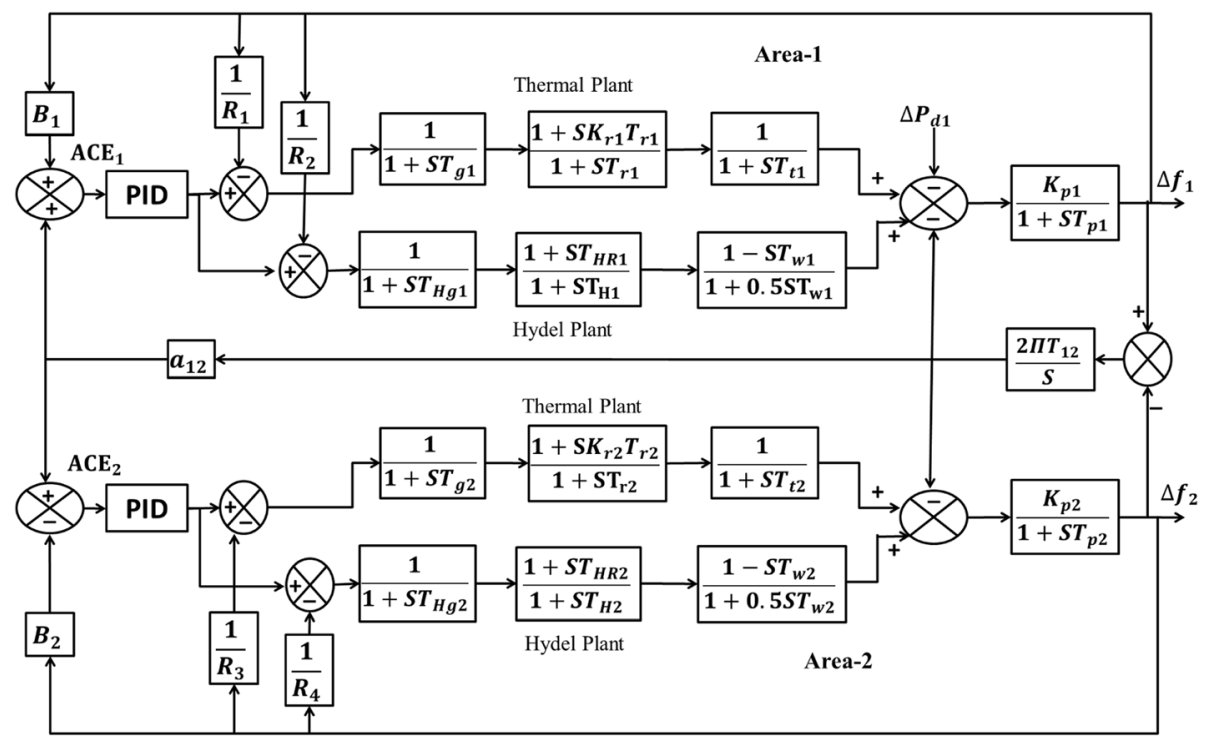

Fig. 2 Two-area hydrothermal system with reheat turbines (test system-2) 


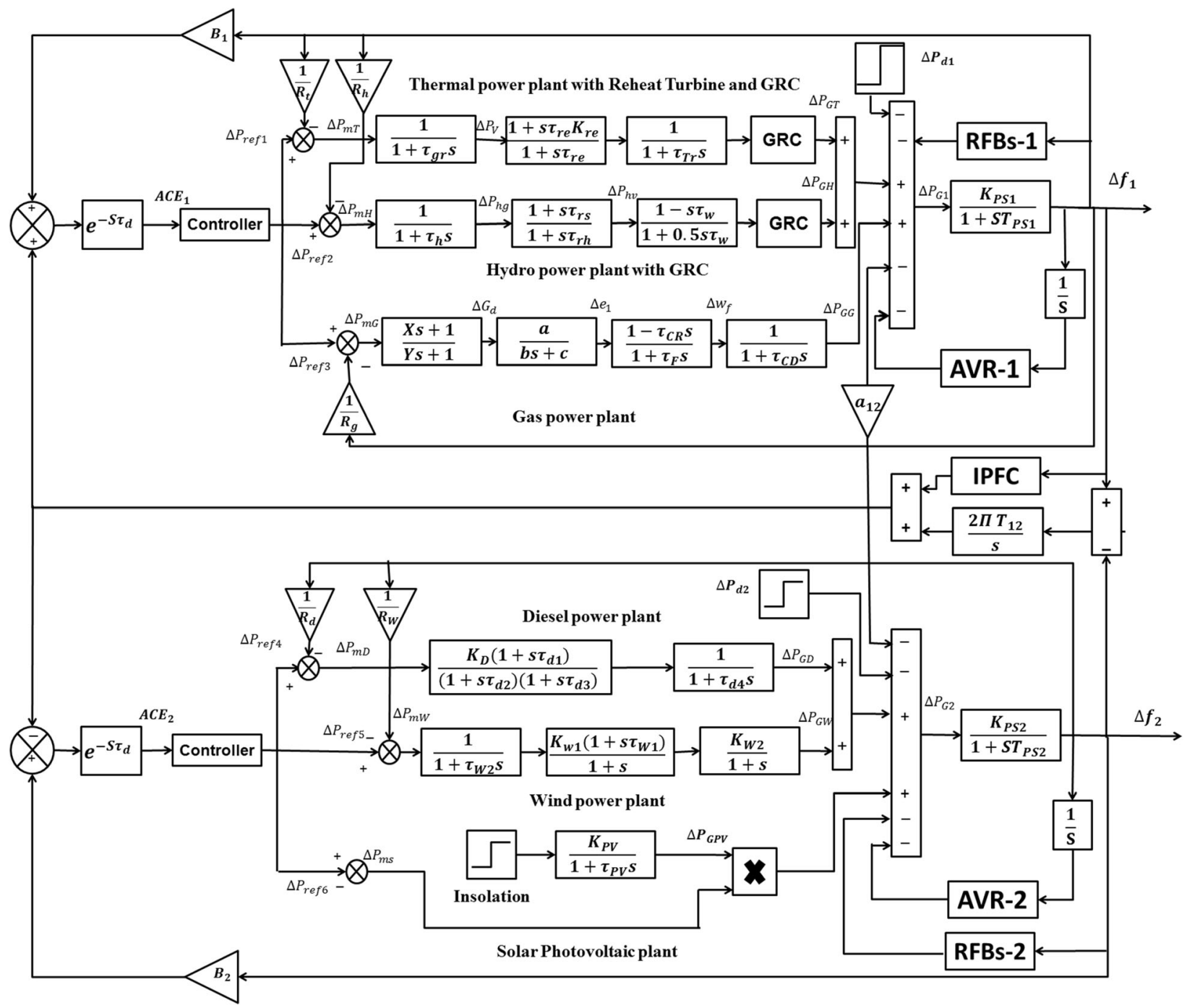

Fig. 3 Two-area combined LFC and AVR model comprising hybrid generation sources considering GRC and CTDs

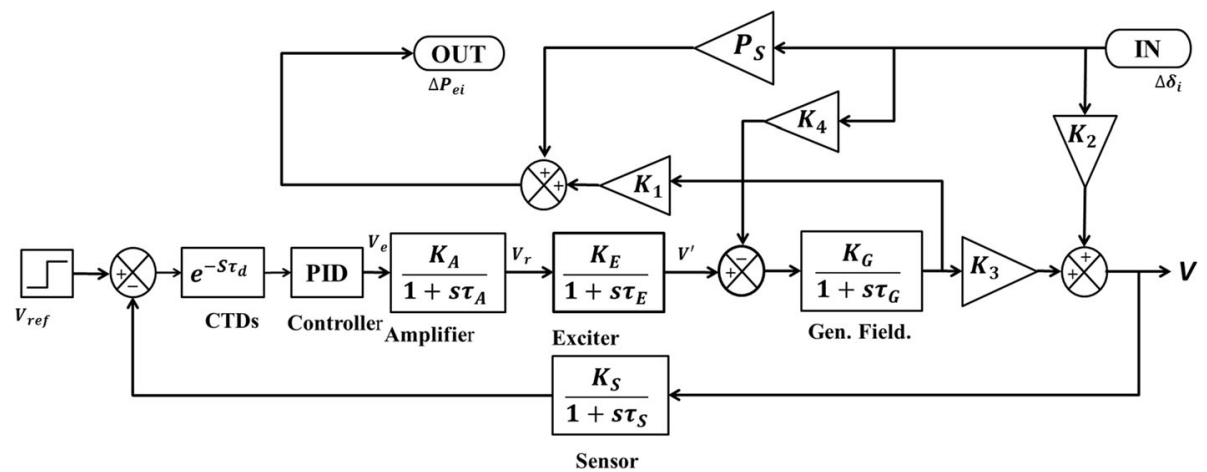

Fig. 4 AVR system with cross coupling coefficients considering CTDs 
where $X_{S}$ and $\delta$ are generator reactance and rotor angle respectively.

In the event of load variation, the frequency fluctuation can be governed by changing the rotor angle $\Delta \delta$ via changing the generation of real power $\Delta P_{e}$ as:

$$
\Delta \mathrm{P}_{\mathrm{e}}=\mathrm{P}_{\mathrm{S}} \Delta \delta+\mathrm{K}_{1} \mathrm{E}^{\prime}
$$

where $\mathrm{P}_{\mathrm{S}}$ is the synchronizing power coefficient. The system terminal voltage $V$ comprises the q-axis $\left(V_{q}\right)$ and $\mathrm{d}$-axis $\left(V_{d}\right)$ components which are influenced by rotor angle. Then terminal voltage is modeled as:

$$
\Delta \mathrm{V}=\mathrm{K}_{2} \Delta \delta+\mathrm{K}_{3} \Delta \mathrm{E}^{\prime}
$$

The factors that regularize the voltage induced in the generator are modeled as:

$$
\mathrm{E}^{\prime}=\frac{\mathrm{K}_{\mathrm{G}}}{1+\mathrm{S \tau}_{\mathrm{G}}}\left(\mathrm{V}^{\prime}-\mathrm{K}_{4} \Delta \delta\right)
$$

where $K_{1}, K_{2}, K_{3}$ and $K_{4}$ are the coefficients that link the AVR with the LFC control loop. The time and gain constants of the subsystem parameters are provided in the Appendix.

\section{Communication time delay}

Modern interconnected power systems are equipped with large numbers of phase measuring units (PMUs) to facilitate the communication between different centers and areas. Usually, several signals are transmitted from generation and transmission systems to load dispatch centers or control centers and from these centers to the generating stations. The transmission and receipt of signals among these centers and stations may affect system stability. As the heart of LFC is the secondary controller which generates the command control signal by taking the area control error (ACE) signal as input, these CTDs can cause delays in input signals to the controllers and consequently delays in command control signal generation. Therefore, alteration of the generator operating set points can be delayed resulting in increased mispatch between demand and generation. This can affect system stability. Thus, CTDs need be taken into consideration to avoid system instability. Thus, here the impact of CTDs on combined frequency and voltage stabilization is analyzed considering the communication delays in test system-3. The communication delay $e^{-s \tau_{d}}$ considered in this work is the transport delay, which is expressed by Taylor series expansion as [23]:

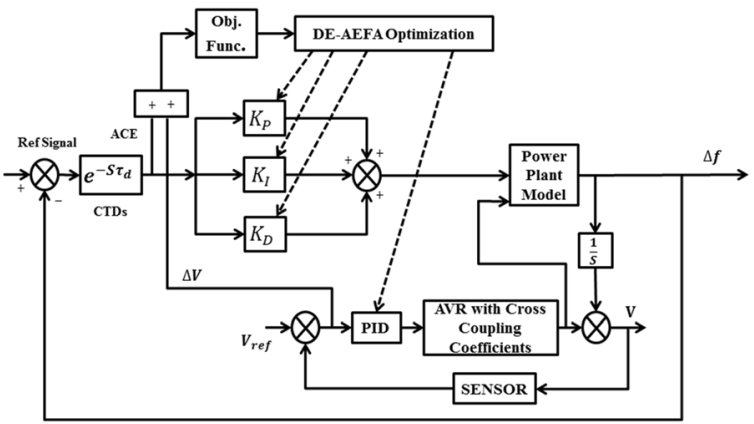

Fig. 5 Tuning of secondary controller with DE-AEFA algorithm

$$
\mathrm{e}^{-\mathrm{s \tau}_{\mathrm{d}}}=\frac{1-\frac{\tau_{d}}{2} \mathrm{~s}}{1+\frac{\tau_{d}}{2} \mathrm{~s}}
$$

\section{Controllers and optimization}

\subsection{Controller structure}

The combined model system is equipped with a classical PID controller as secondary regulator, since almost $90 \%$

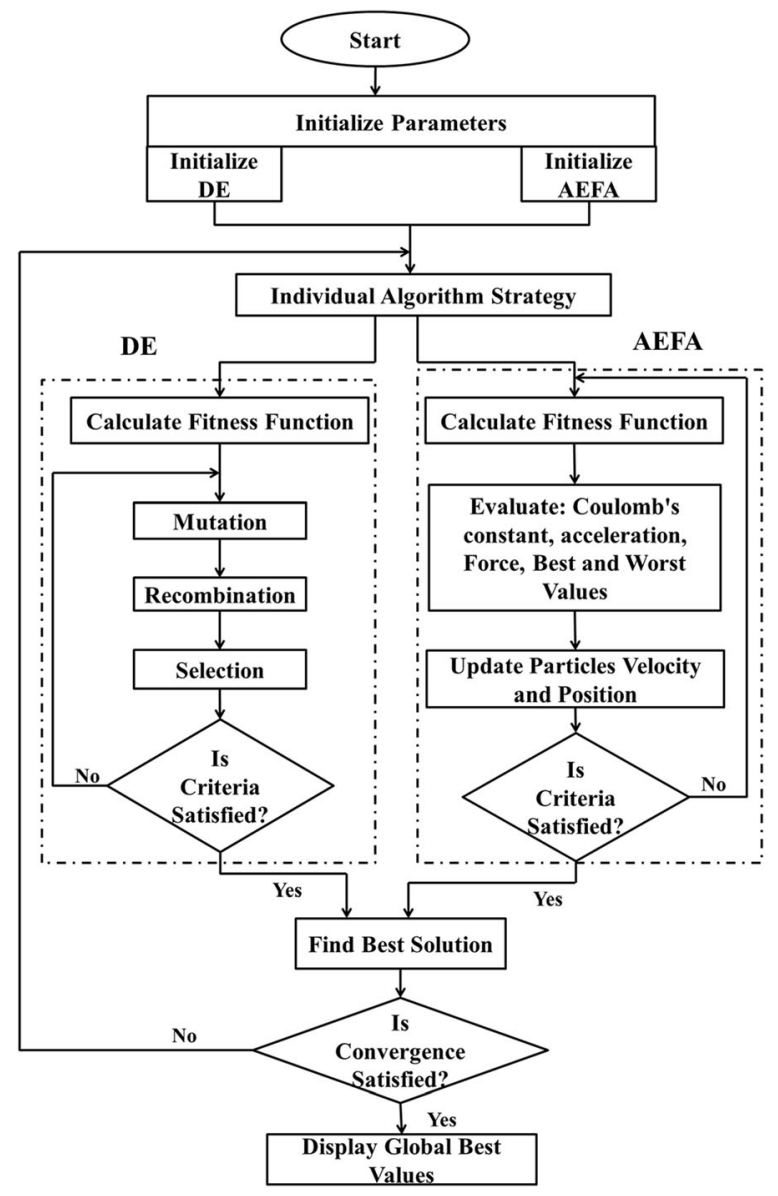

Fig. 6 Flow chart of the DE-AEFA algorithm 
Table 1 Comparison of optimal solutions obtained from different optimization algorithms

\begin{tabular}{lllll}
\hline S.No & Parameters & DE & AEFA & DE-AEFA \\
\hline 1 & $x$ & 3.002461 & 2.993744 & 2.999176 \\
2 & $y$ & 1.982402 & 2.004345 & 2.000937 \\
3 & Function Value & 0.00458 & 0.001223 & $2.46 \mathrm{E}-05$ \\
\hline
\end{tabular}

of manufacturing industries are still using this for controlling purpose because of design simplicity and efficiency. The input signals to these controllers are ACE signals while the parametric gains are tuned using DEAEFA with respect to the error squared over the integral (ISE) objective function given in (6). The output control signals $\Delta P_{C} \Delta P_{C}$ from these secondary controllers are fed to the generating plants. The schematic representation of PID tuning in the considered combined system is depicted in Fig. 5.

$$
J=\int_{0}^{T_{\text {sim }}}\left[\Delta f_{1}^{2}+\Delta f_{2}^{2}+\Delta P_{\text {tiel }, 2}^{2}+\Delta V_{1}^{2}+\Delta V_{2}^{2}\right] d t
$$

The PID controller gains in the two areas are optimized using the proposed algorithm subjected to constraints.

\subsection{DE-AEFA searching strategy}

$\mathrm{DE}$ was proposed in [24] and belongs to the category of a stochastic search method. In DE, the initial population is randomly generated within predefined limits while the next generation's new population is generated by making use of mutation, recombination and selection operators.
A recombination operator then adjudicates the population continuously to drive towards the best solution, whereas the mutation operator tries to disseminate the population in uncovered search space to locate the best optimum solution. In [25] the performance of DE is tested on several benchmark functions, and this reveals that the DE algorithm is efficient in solving nonlinear and multi-modal objective functions. The benefits of $\mathrm{DE}$ include the potential of generating new population utilizing targets and mutant vector properties and the feature of elitism to avoid destroying the best solution when creating the next generation. However, weakness in local searching, failure in maintaining average equilibrium between exploitation and exploration, and having a tendency towards slow and premature convergence limit the application boundary.

The AEFA algorithm was proposed in [26] and was inspired by the concept of electrostatic force. In the AEFA algorithm, the charged particles act as searching agents, while the attraction and repulsion forces between these particles result in the moving of objects in search space. Hence, the positions of these charged particles are taken as problem solutions and the particle with the highest charge is believed to be best individual who attracts other charged particles and slowly moves in search space. Initialization of the AEFA is quite simple and requires only a few initial parameters. However, although the AEFA algorithm can locate near optimal solutions with high convergence speed by exerting equilibrium between exploitation and exploration, it is inferior to DE in global convergence and ease of use. The main drawback of the AEFA algorithm is its way of adjusting the step size in updating particle velocity and position. This may lead to untimely

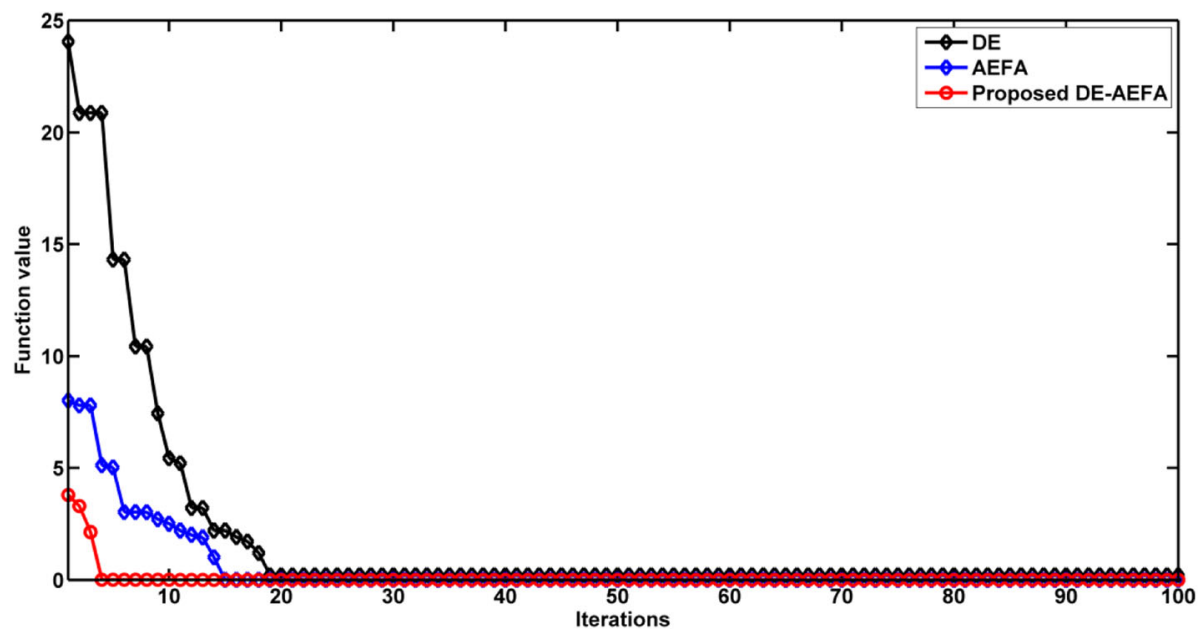

Fig. 7 Convergence characteristics of optimization algorithms tested on Himmelblau's function 


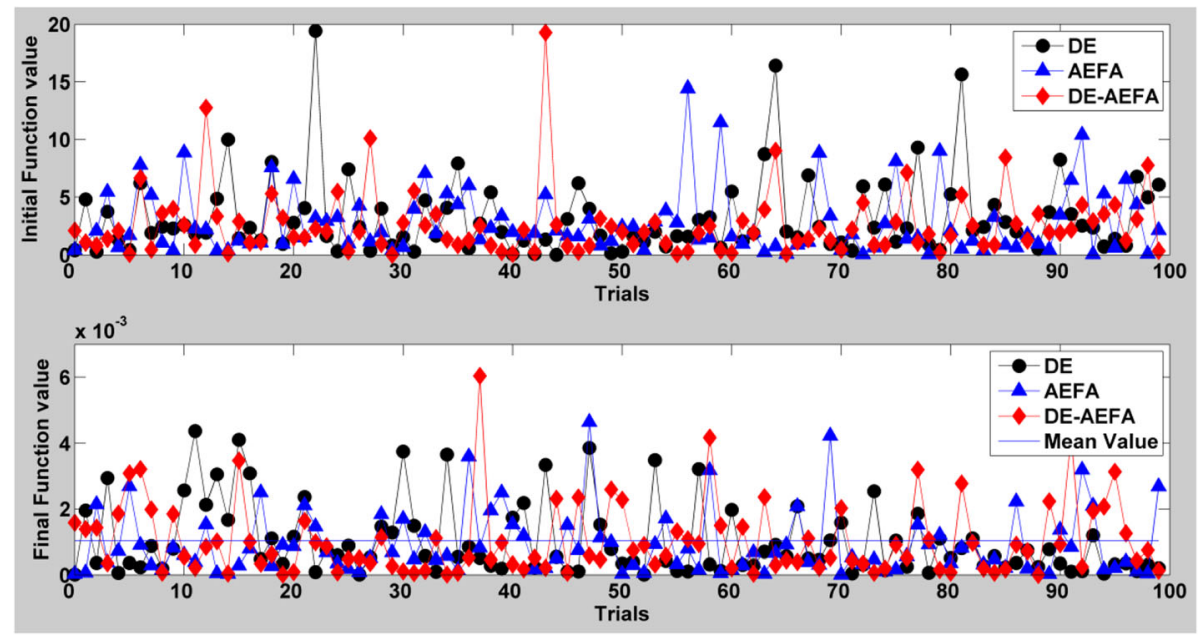

Fig. 8 Variations of initial and final values of sphere function for 100 trials

convergence, since the update of velocity and position in AEFA mainly relies on repulsion and attraction of charged particles.

Searching for the best optimal solution for a more realistic nonlinear power system needs proper initialization of initial parameters. Small deviations in initial parameters can lead to large variations in algorithmic efficiency. The problem formulated in this work, i.e., multi-area LFC and AVR combined model having hybrid generating sources considering CTDs, is a complex one, and thus a new and efficient algorithm is required. Hence, a new DE-AEFA optimization is presented in this work achieved by the complementary performance of DE and AEFA algorithms in overcoming the disadvantages of individual ones and to effectively make use of individual benefits.

The proposed DE-AEFA algorithm as depicted in Fig. 6 combines the evolutionary concept of $\mathrm{DE}$ with the charged particle-based searching strategy of the AEFA algorithm. The DE-AEFA algorithm has two levels, i.e., the DE level and the AEFA level. Throughout the searching process, half of the individuals obtain a solution using the DE strategy while the other half uses the AEFA searching mechanism. Thus, the total information of each population is shared among every individual agent. The individual with best fitness value then acquires the chance of getting into optimization of the next generation. Hence, this proposed approach inherits the efficiency of searching procedure while also assuring global convergence.

The procedural flow of the DE-AEFA algorithm is as follows:

Step 1: Randomly initialize the initial parameters in DE and AEFA algorithms.
Step 2: Initialize the population of DE and AEFA individually.

Step 3: Calculate cost function value of each population and consider the population sets which give the highest fitness values as the global best parameters.

Step 4: From Step 3, only the population with the highest fitness value persists and other individuals are rejected.

Step 5: The searching mechanism of the DE and AEFA algorithms moves on to the persisted individuals as mentioned in Step 4.

- AEFA phase: Particle velocities and positions are updated as given in [26].

- DE phase: Mutation, recombination and selection operations are performed.

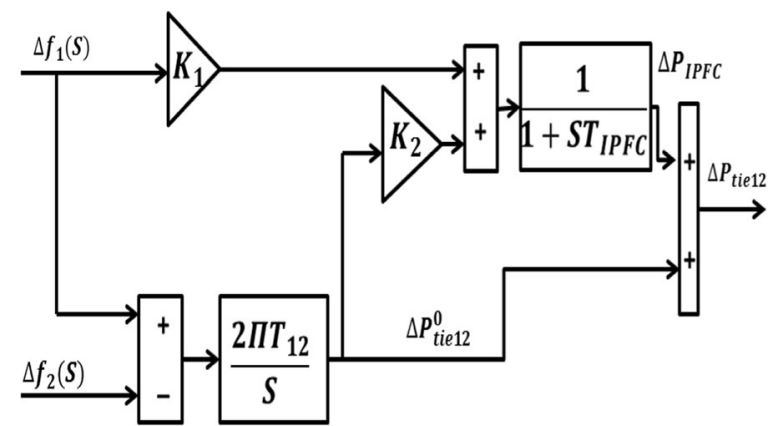

Fig. 9 Structure of IPFC as damping controller 
Table 2 Optimum parameters of PID controller for test system-1

\begin{tabular}{|c|c|c|c|c|c|c|c|}
\hline \multirow[t]{2}{*}{ Parameters } & \multicolumn{7}{|c|}{ Optimization algorithms } \\
\hline & DE-AEFA & HGA-PSO [3] & AEFA & GWO [2] & BSA [19] & $\mathrm{DE}$ & PSO [17] \\
\hline$\overline{K_{P 1}}$ & 1.9757 & 1.6476 & 1.5447 & 1.2278 & 0.9160 & 0.9296 & 0.7579 \\
\hline $\mathrm{K}_{\mathrm{p} 2}$ & 1.8296 & 1.7762 & 1.6413 & 1.2467 & 0.9398 & 1.0021 & 0.8779 \\
\hline$K_{11}$ & 0.0098 & 0.0445 & 0.0358 & 0.0050 & 0.0550 & 0.0209 & 0.3016 \\
\hline$K_{12}$ & 0.0137 & 0.0412 & 0.0091 & 0.0196 & 0.0012 & 0.0190 & 0.3016 \\
\hline$K_{D 1}$ & 1.0621 & 0.7210 & 0.9074 & 0.9149 & 0.7291 & 0.5860 & 0.1263 \\
\hline$K_{D 2}$ & 1.1428 & 0.7635 & 1.0911 & 0.8536 & 0.6922 & 0.5747 & 0.1372 \\
\hline ISE & 0.1043 & 0.4109 & 0.6097 & 0.8725 & 1.0857 & 1.0943 & 1.7010 \\
\hline Settling time: $\Delta f_{1}$ & 2.724 & 4.141 & 4.890 & 7.485 & 7.981 & 8.962 & 9.752 \\
\hline Settling time: $\Delta \mathrm{P}_{\mathrm{Tie}}$ & 5.126 & 6.207 & 8.470 & 8.573 & 8.738 & 9.323 & 9.693 \\
\hline Settling time: $\Delta f_{2}$ & 3.214 & 4.276 & 4.991 & 5.184 & 8.275 & 8.708 & 9.752 \\
\hline
\end{tabular}

Step 6: Inspect the deduced solutions. If stopping criteria are met, stop the iterations and display the best optimal solution. Otherwise go to Step 3.

The execution of the proposed DE-AEFA algorithm is examined on several standard benchmark functions and the outcomes on Himmelblau's function given in (7) are noted in Table 1. It is emphasized that the function value with the proposed algorithm is improved by $94.6 \%$ with DE and $79.88 \%$ with AEFA, while the obtained optimum values with the proposed DE-AEFA hardly deviate from standard global minimum values. The convergence characteristics of the optimization algorithms tested on Himmelblau's function are compared in Fig. 7. It reveals that the DE-AEFA convergence start with a
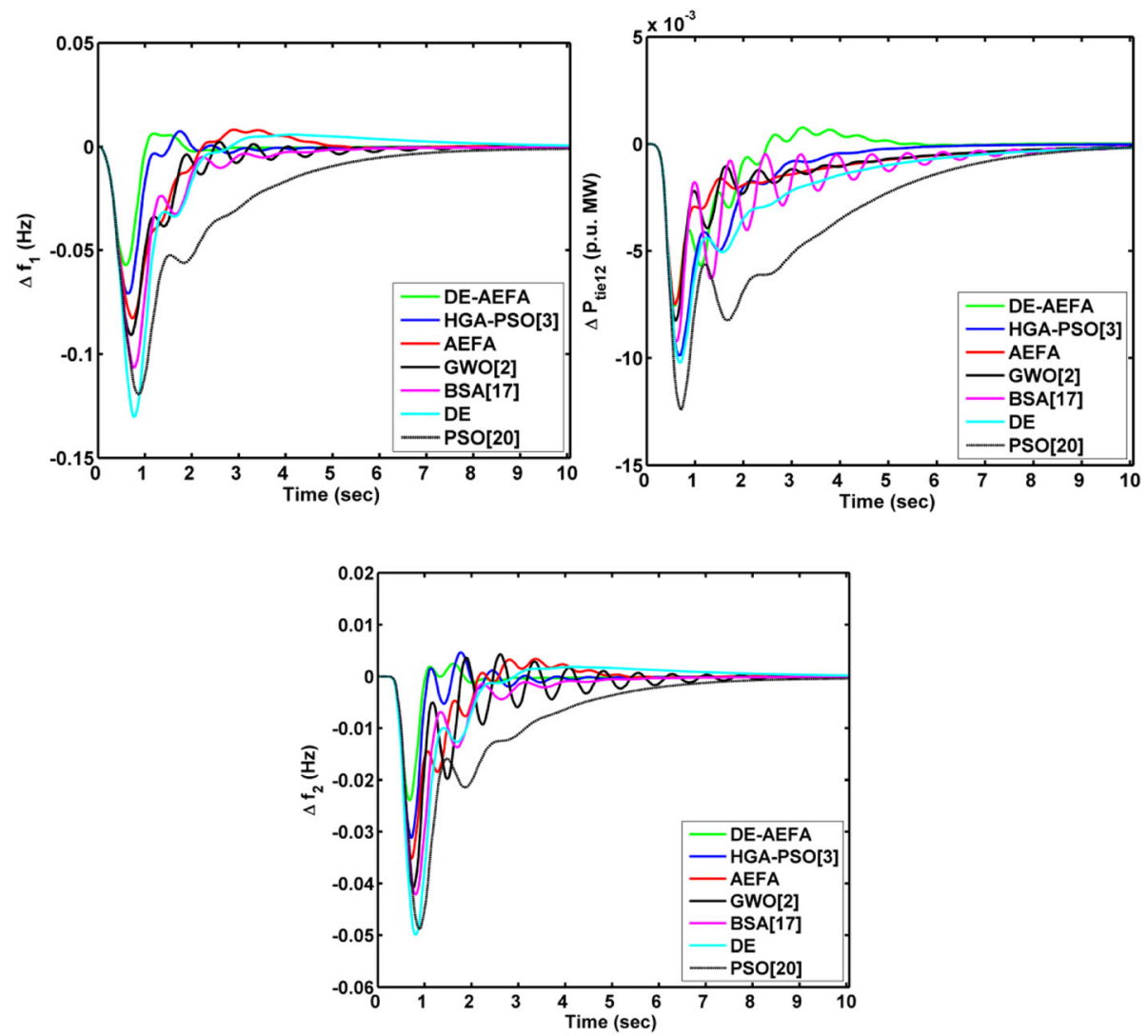

Fig. 10 Test system-1 responses 

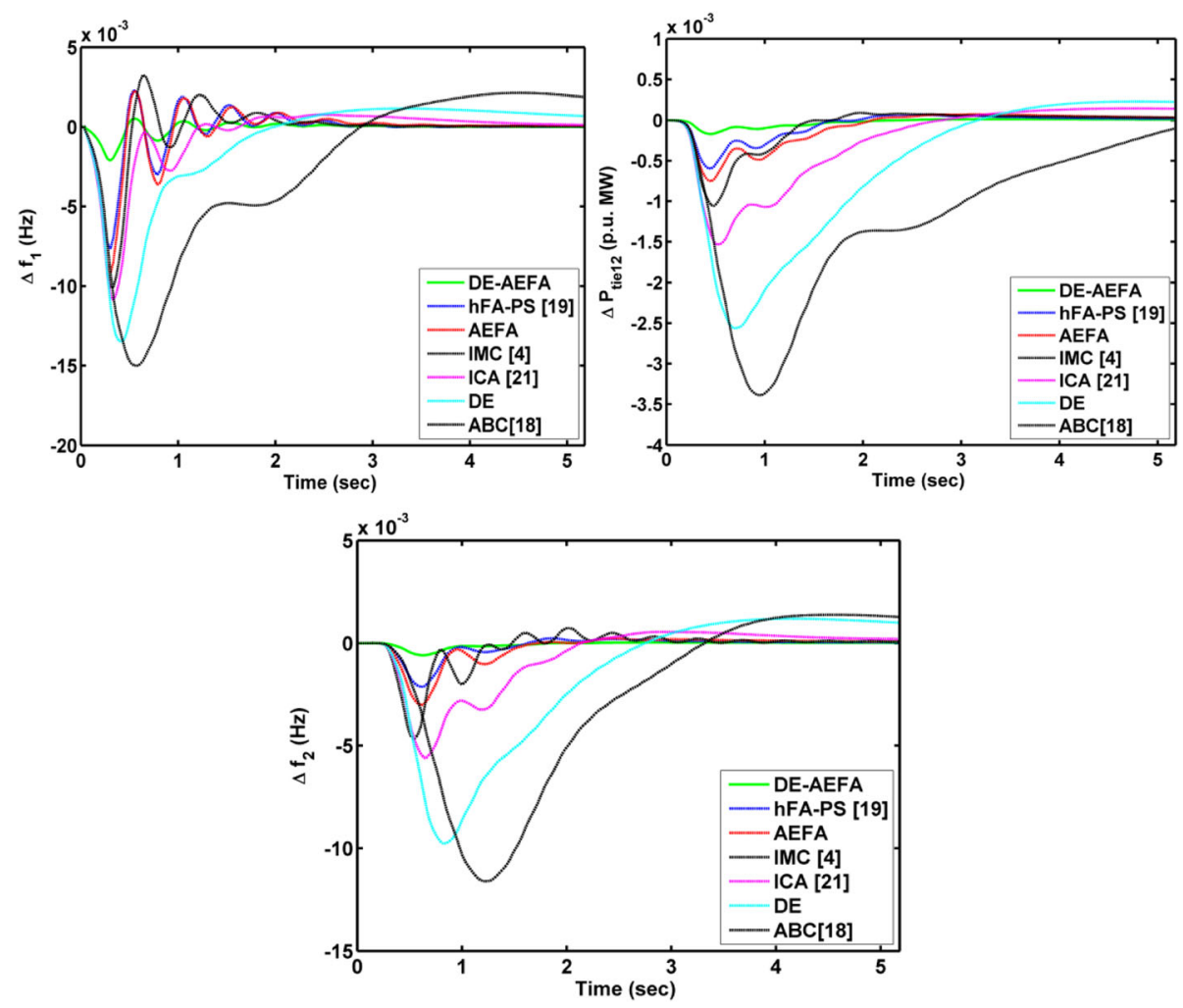

Fig. 11 Test system-2 responses

beneficial objective value and the final beneficial value is obtained after a very low number of iterations when compared to other methods. To validate the efficacy of the presented approach, it is tested on a sphere function given in (8) for 100 trials. Figure 8 shows the variations of function values at initial and final positions under DE, AEFA and DE-AEFA algorithms for the 100 trials. It is observed from Fig. 8 that the final function values are below their average values for most of the trials under the proposed DE-AEFA method.

$$
f(x, y)=\left(x^{2}+y-11\right)^{2}+\left(x+y^{2}-7\right)^{2}
$$

Sphere function $=\sum_{i=1}^{2} x_{i}^{2}$

Table 3 Optimum parameters of PID controller for test system-2

\begin{tabular}{llllllll}
\hline Parameters & \multicolumn{2}{l}{ Optimization algorithms } & & & \\
\cline { 2 - 7 } & DE-AEFA & hFA-PS [21] & AEFA & IMC [4] & ICA [20] & DE & ABC [18] \\
\hline$K_{\text {P1 }}$ & 3.9957 & 3.9875 & 3.4898 & 4.2105 & 2.9105 & 2.7060 & 2.8147 \\
$K_{P 2}$ & 4.0138 & 3.9085 & 3.4387 & 4.2105 & 2.7925 & 2.8903 & 2.6324 \\
$K_{11}$ & 2.7416 & 2.9134 & 2.0357 & 7.5328 & 2.6676 & 1.9767 & 1.9134 \\
$K_{12}$ & 2.9292 & 2.6432 & 2.1419 & 7.5328 & 1.9936 & 1.7630 & 1.8003 \\
$K_{D 1}$ & 2.0935 & 2.1712 & 1.1270 & 1.2936 & 0.0524 & 0.9157 & 0.6160 \\
$K_{D 2}$ & 1.9569 & 2.0975 & 1.2697 & 1.2936 & 0.0753 & 1.0136 & 0.6551 \\
ISE & 0.0344 & 0.0632 & 0.0972 & 0.2769 & 0.9649 & 1.0540 & 1.1299 \\
Settling time: $\Delta f_{1}$ & 2.506 & 2.930 & 3.985 & 4.758 & 7.788 & 17.91 & 23.64 \\
Settling time: $\Delta \mathrm{P}_{\text {Tie }}$ & 2.335 & 4.107 & 4.587 & 6.323 & 9.113 & 15.72 & 21.79 \\
Settling time: $\Delta f_{2}$ & 2.237 & 3.657 & 4.522 & 8.009 & 9.059 & 12.64 & 22.69 \\
\hline
\end{tabular}




\section{Interline power flow controller}

IPFC focuses on compensation of multiple lines at given sub-station. In general, IPFC engages many DC to AC converters allowed with a DC link in common. With the provision of DC link common arrangement, IPFC facilitates control over active power among DC link and own transmission line in addition to independent reactive series compensation. Hence, the operational performance of the entire interconnected system is improved by IPFC incorporation. IPFC is superior to other thyristor and SSSC-based controllers. The structure of IPFC used in this work is shown in Fig. 9.

The change in tie-line power exchange for the IPFC controller is expressed as:

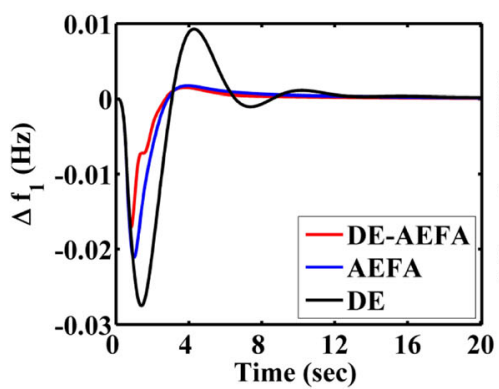

(a)

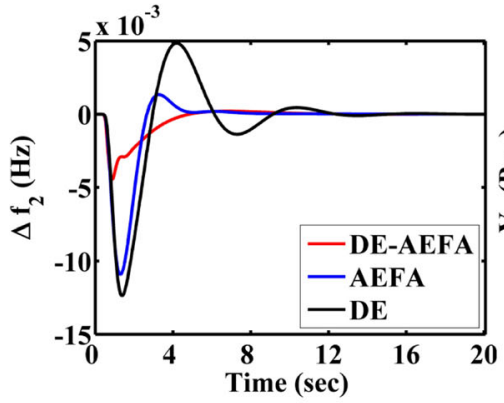

(c)

$$
\Delta \mathrm{P}_{\text {tie12 }}(\mathrm{S})=\Delta \mathrm{P}_{\text {tie12 }}^{0}(\mathrm{~S})+\Delta \mathrm{P}_{\text {IPFC }}(\mathrm{S})
$$

The impact of the IPFC on power flow through the tie-line can be modelled as:

$$
\Delta \mathrm{P}_{\mathrm{IPFC}}(\mathrm{S})=\left(\frac{1}{1+\mathrm{ST}_{\mathrm{IPFC}}}\right)\left(\begin{array}{l}
\mathrm{K}_{1} \Delta \mathrm{f}_{1}(S) \\
+K_{2} \Delta P_{\text {tie12 }}^{0}(S)
\end{array}\right)
$$

The incremental change in power injected by the IPFC $\left(\Delta \mathrm{P}_{\mathrm{IPFC}}\right)$ into the line is to compensate the line power flow, and so that oscillations in the tie-line can be mitigated effectively.

\section{Redox flow batteries (RFBs)}

RFBs are electro-chemical rechargeable energy storage devices (ESDs) suited for a wide range of applications.

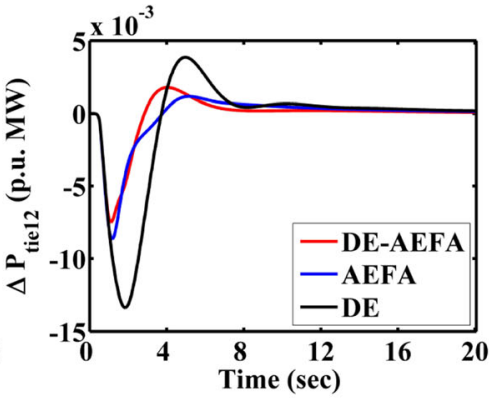

(b)

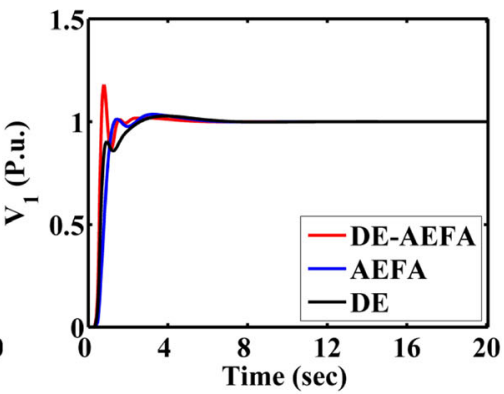

(d)

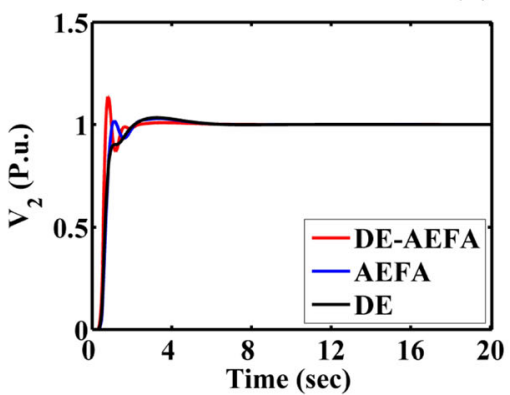

(e)

Fig. 12 Dynamic responses of combined LFC and AVR model (test system-3) without considering CTDs: a $\Delta f_{1} ; \mathbf{b} \Delta P_{\text {tie12; }}$ c $\Delta f_{2} ; \mathbf{d}$ $V_{1} ; \mathbf{e} V_{2}$ 
Table 4 Numerical results for responses of combined LFC and AVR model with and without considering CTDs

\begin{tabular}{|c|c|c|c|c|c|c|c|c|}
\hline & Optimization Algorithms & Parameters & $\begin{array}{l}\Delta \mathbf{f}_{1} \\
* 10^{-3}\end{array}$ & $\begin{array}{l}\Delta \mathrm{f}_{2} \\
* 10^{-3}\end{array}$ & $\begin{array}{l}\Delta \mathrm{P}_{\text {tie } 12} \\
* 10^{-3}\end{array}$ & $\mathrm{~V}_{1}$ & $v_{2}$ & ISE \\
\hline \multirow[t]{9}{*}{ Without considering CTDs } & $\mathrm{DE}$ & TS (Sec) & 17.23 & 14.09 & 17.11 & 5.842 & 5.889 & 25.725 \\
\hline & & PU (-ve) & 27.47 & 12.29 & 13.28 & 0.857 & 0.910 & \\
\hline & & $\mathrm{PO}$ & 9.269 & 4.847 & 3.851 & 1.028 & 1.034 & \\
\hline & AEFA & TS (Sec) & 9.591 & 9.268 & 12.80 & 5.515 & 5.833 & 21.478 \\
\hline & & PU (-ve) & 20.55 & 10.81 & 8.521 & 0.976 & 0.944 & \\
\hline & & PO & 1.715 & 1.335 & 1.161 & 1.037 & 1.033 & \\
\hline & DE-AEFA & TS (Sec) & 7.575 & 7.520 & 7.847 & 5.070 & 4.734 & 12.416 \\
\hline & & PU (-ve) & 16.70 & 4.391 & 7.428 & 0.870 & 0.873 & \\
\hline & & $\mathrm{PO}$ & 1.658 & 0.1573 & 1.766 & 1.181 & 1.135 & \\
\hline \multirow[t]{9}{*}{ With considering CTDs } & DE & TS (Sec) & 22.50 & 17.86 & 21.56 & 7.581 & 10.45 & 94.784 \\
\hline & & PU (-ve) & 61.09 & 14.81 & 34.56 & 0.771 & 0.692 & \\
\hline & & $\mathrm{PO}$ & 23.81 & 5.041 & 12.68 & 1.407 & 1.386 & \\
\hline & AEFA & TS (Sec) & 10.68 & 13.29 & 14.26 & 7.024 & 6.845 & 48.272 \\
\hline & & PU (-ve) & 42.43 & 9.547 & 20.96 & 0.578 & 0.784 & \\
\hline & & $\mathrm{PO}$ & 10.06 & 1.933 & 3.454 & 1.352 & 1.472 & \\
\hline & DE-AEFA & TS (Sec) & 8.42 & 10.77 & 12.65 & 5.154 & 5.020 & 24.921 \\
\hline & & PU (-ve) & 33.39 & 7.200 & 15.62 & 0.711 & 0.745 & \\
\hline & & PO & 9.235 & 0.722 & 2.106 & 1.429 & 1.428 & \\
\hline
\end{tabular}

In RFBs, sulphuric acid is used as the electrolyte solution which has vanadium ions and fills the reactor tank. The reactor tank has two compartments separated by a membrane. Each compartment is equipped with a pump to facilitate the circulation of the electrolyte through battery cells. The battery charging and discharging process is through reduction-oxidation (redox) reaction. The efficiency of RFBs increases as the charging/discharging cycle period becomes shorter, while RFBs are not aged by frequent usage and have a quick response equivalent to superconducting magnetic energy storage devices. In general, ESD charges under normal loading conditions and delivers the energy back to the system when there is sudden rise in load. This can be done effectively and instantly through RFBs because of their quick response characteristics. Thus, RFBs can play a key role in sustaining system frequency by regulating the real power mismatch between control areas, and are recommended in power systems to improve the quality

Table 5 Optimal controller gains in test system-3 with and without considering CTDs

\begin{tabular}{|c|c|c|c|c|c|c|c|c|}
\hline \multirow[t]{3}{*}{ Controller } & \multicolumn{4}{|c|}{ Without Considering CTDs } & \multicolumn{4}{|c|}{ with Considering CTDs } \\
\hline & \multicolumn{2}{|l|}{ Area-1 } & \multicolumn{2}{|l|}{ Area-2 } & \multicolumn{2}{|l|}{ Area-1 } & \multicolumn{2}{|l|}{ Area-2 } \\
\hline & Loop LFC & Loop AVR & Loop LFC & Loop AVR & Loop LFC & Loop AVR & Loop LFC & Loop AVR \\
\hline \multirow[t]{3}{*}{ DE: PID } & $K_{p}=3.0963$ & $K_{p}=2.1076$ & $K_{p}=3.4047$ & $K_{p}=1.9587$ & $K_{p}=3.4632$ & $K_{p}=2.0209$ & $K_{p}=3.7258$ & $K_{p}=1.7819$ \\
\hline & $K_{1}=2.9147$ & $K_{1}=1.6913$ & $K_{1}=2.6738$ & $K_{I}=1.6627$ & $K_{1}=2.7610$ & $K_{1}=1.6914$ & $K_{1}=2.3726$ & $K_{I}=1.6733$ \\
\hline & $K_{D}=1.2009$ & $K_{D}=0.9126$ & $K_{D}=1.9844$ & $K_{D}=0.9852$ & $K_{D}=1.6035$ & $K_{D}=0.7521$ & $K_{D}=2.0015$ & $K_{D}=1.1343$ \\
\hline \multirow[t]{3}{*}{ AEFA: PID } & $K_{p}=3.9752$ & $K_{p}=2.4194$ & $K_{p}=3.7805$ & $K_{p}=2.0357$ & $K_{p}=4.2938$ & $K_{p}=2.8621$ & $K_{p}=3.9990$ & $K_{p}=3.0986$ \\
\hline & $K_{1}=2.4588$ & $K_{1}=1.4389$ & $K_{1}=2.9595$ & $K_{1}=1.8419$ & $K_{1}=2.5841$ & $K_{1}=1.5276$ & $K_{1}=2.7256$ & $K_{1}=1.8667$ \\
\hline & $K_{D}=1.8030$ & $K_{D}=0.9209$ & $K_{D}=1.6575$ & $K_{D}=0.9304$ & $K_{D}=2.0137$ & $K_{D}=1.2961$ & $K_{D}=1.5786$ & $K_{D}=1.1048$ \\
\hline \multirow[t]{3}{*}{ DE-AEFA: PID } & $K_{p}=4.0786$ & $K_{p}=2.3922$ & $K_{p}=3.6959$ & $K_{p}=2.0572$ & $K_{p}=4.7219$ & $K_{p}=2.5713$ & $K_{p}=4.5923$ & $K_{p}=2.5312$ \\
\hline & $K_{1}=2.7907$ & $K_{1}=1.5666$ & $K_{l}=3.3108$ & $K_{1}=2.0963$ & $K_{1}=3.0172$ & $K_{1}=1.9218$ & $K_{1}=3.4598$ & $K_{1}=2.1006$ \\
\hline & $K_{D}=2.0413$ & $K_{D}=1.1921$ & $K_{D}=2.2699$ & $K_{D}=1.8385$ & $K_{D}=2.2819$ & $K_{D}=1.9054$ & $K_{D}=2.4885$ & $K_{D}=2.0862$ \\
\hline
\end{tabular}


of power generated through hybrid energy sources. The transfer function model of RFBs implemented in this work is from [27] and described in Eq. (11). The parameters of RFBs are listed in the Appendix.

$$
\mathrm{G}_{\mathrm{RFB}}=\frac{\mathrm{K}_{\mathrm{RFB}}}{1+\mathrm{ST}_{\mathrm{RFB}}}
$$

\section{Results and discussion}

\subsection{Test system-1 dynamic analysis}

In this sub section, a two-area with equal generation capacity of thermal power plant having a non-reheat turbine structure (test system-1) is considered. The test system-1 as depicted in Fig. 1 and the pertinent data in the Appendix is designed in SIMULINK. A classical PID controller is used and is simulated for $1 \%$ step load perturbation (SLP) on area-1 at $\mathrm{t}=0 \mathrm{~s}$.
Responses of the system are analyzed in terms of deviations in area-1 frequency $\Delta f_{1} \Delta f_{1}$, tie-line power $\Delta P_{\text {tie12 }}$ and area-2 frequency $\Delta f_{2}$. The controller gains are tuned with DE-AEFA optimization and are tabulated in Table 2 while the corresponding system dynamic variations are depicted in Fig. 10.

The performance of the presented DE-AEFA strategy is compared with other optimization algorithmbased controllers that are available such as PSO [17], GWO [2], BSA [19] and HGA-PSO [3] tuned PID controllers. From Fig. 10, it is clear that the proposed control approach offers better results in settling time $\left(\mathrm{T}_{\mathrm{s}}\right)$ and diminishing oscillation. The proposed controller is further examined quantitatively and the calculated objective index values are noted in Table 2 . As can be seen, the performance index values are significantly reduced with the proposed strategy compared to other approaches, because of the combined

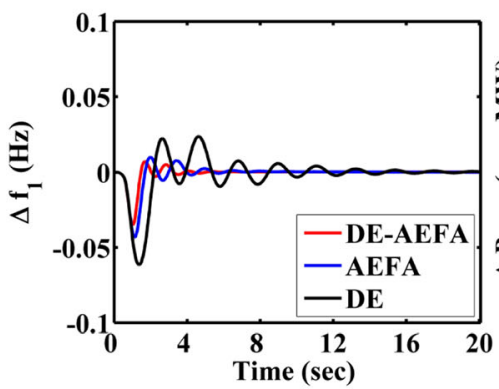

(a)

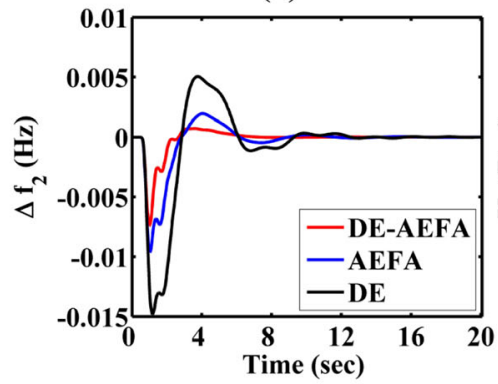

(c)

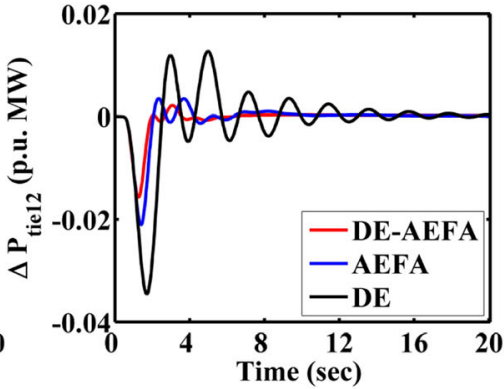

(b)

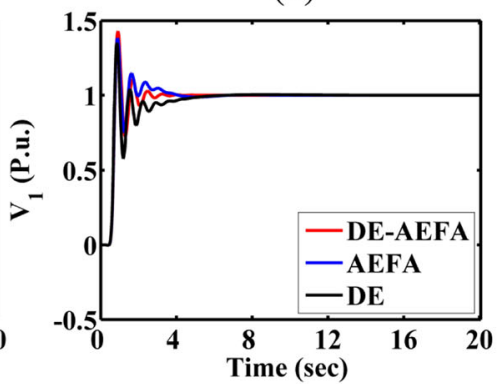

(d)

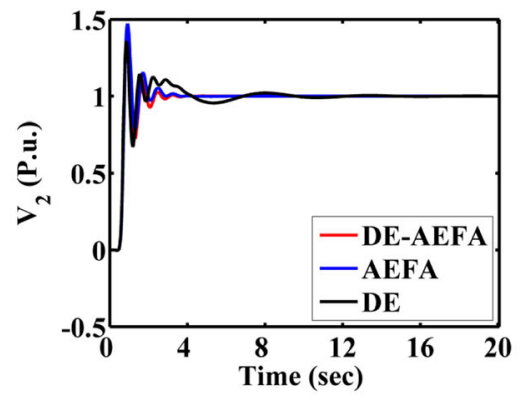

(e)

Fig. 13 Dynamic responses of combined LFC and AVR model (test system-3) considering CTDs: a $\Delta f_{1} ; \mathbf{b} \Delta \mathrm{P}_{\text {tie } 12 ;} \mathbf{c} \Delta \mathrm{f}_{2} ; \mathbf{d} V_{1} ; \mathbf{e} V_{2}$ 


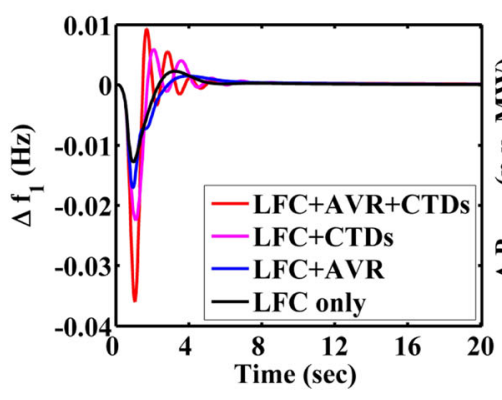

(a)

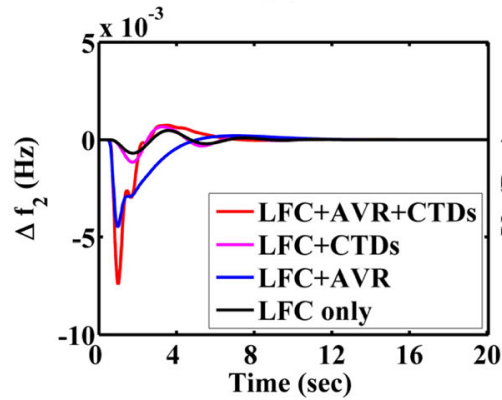

(c)

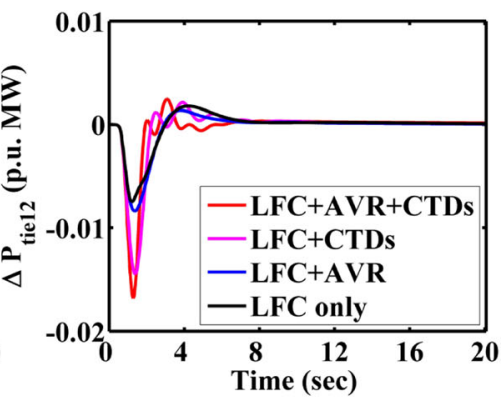

(b)

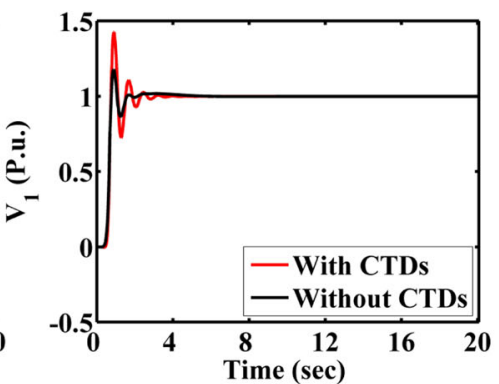

(d)

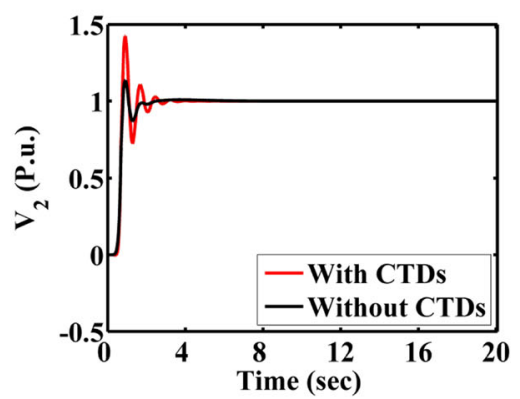

(e)

Fig. 14 Dynamic responses of test system-3 with and without considering AVR coupling and CTDs under the control of DE-AEFA based PID controller: a $\Delta \mathrm{f}_{1} ; \mathbf{b} \Delta \mathrm{P}_{\text {tie } 12} ; \mathbf{c} \Delta \mathrm{f}_{2} ; \mathbf{d} \mathrm{V}_{1} ; \mathbf{e} \mathrm{V}_{2}$

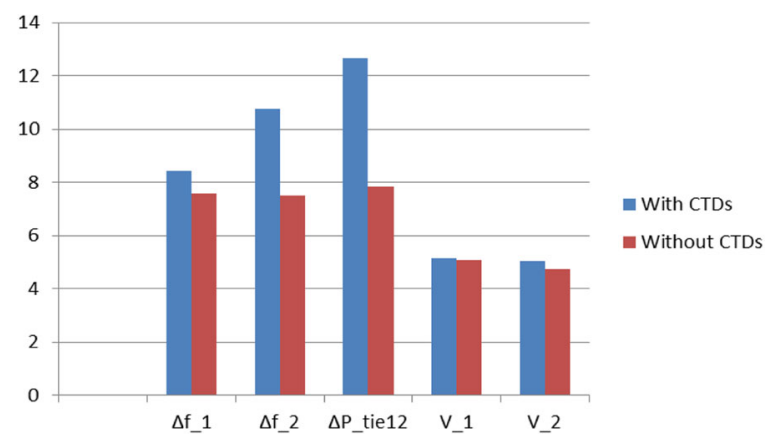

Fig. 15 Settling time of combined LFC and AVR responses with and without considering CTDs inherent qualities of the DE and AEFA algorithms in the presented strategy.

\subsection{Test system-2 dynamic analysis}

The effectiveness of the presented DE-AEFA algorithmbased controller is manifested by the test system of two equal areas consisting of a reheat turbine structure of hydrothermal units, a system which is widely described in the literature. The test system- 2 transfer function model is rendered in Fig. 2. The dynamics of system behavior are analyzed by inducing $1 \%$ SLP in area- 1 at $\mathrm{t}=0 \mathrm{~s}$, and the responses are analyzed in terms of $\Delta f_{1}, \Delta P_{\text {tie12 }} \Delta f_{1}$ and $\Delta f_{2} \Delta f_{2}$ as shown in Fig. 11.

The system dynamics of the DE-AEFA optimized PID controller are compared with those of other 
Table 6 Optimum values of controller under coordinated control strategy

\begin{tabular}{|c|c|c|c|c|c|}
\hline \multirow[t]{2}{*}{ Controller } & \multicolumn{2}{|l|}{ Area-1 } & \multicolumn{2}{|l|}{ Area-2 } & \multirow{2}{*}{$\begin{array}{l}\text { Device } \\
\text { parameters }\end{array}$} \\
\hline & Loop LFC & Loop AVR & Loop LFC & Loop AVR & \\
\hline DE-AEFA: PID & $\begin{array}{l}K_{P}=4.0786 \\
K_{I}=2.7907 \\
K_{D}=2.0413\end{array}$ & $\begin{array}{l}K_{P}=2.3922 \\
K_{I}=1.5666 \\
K_{D}=1.1921\end{array}$ & $\begin{array}{l}K_{P}=3.6959 \\
K_{I}=3.3108 \\
K_{D}=2.2699\end{array}$ & $\begin{array}{l}K_{p}=2.0572 \\
K_{I}=2.0963 \\
K_{D}=1.8385\end{array}$ & - \\
\hline DE-AEFA: PID with RFBs only & $\begin{array}{l}K_{P}=3.6983 \\
K_{1}=2.1317 \\
K_{D}=1.9620\end{array}$ & $\begin{array}{l}K_{P}=1.7751 \\
K_{1}=2.1906 \\
K_{D}=0.8502\end{array}$ & $\begin{array}{l}K_{p}=4.0214 \\
K_{I}=3.3378 \\
K_{D}=2.3791\end{array}$ & $\begin{array}{l}K_{p}=2.4988 \\
K_{I}=2.4557 \\
K_{D}=1.6560\end{array}$ & $\begin{array}{l}\mathrm{K}_{\mathrm{RBF} 1}=1.017, \mathrm{~K}_{\mathrm{RBF2}}=0.903 \\
\mathrm{~T}_{\mathrm{RBF} 1}=0.999, \mathrm{~T}_{\mathrm{RBF} 2}=1.000\end{array}$ \\
\hline DE-AEFA: PID with IPFC-RFBs & $\begin{array}{l}K_{p}=4.8141 \\
K_{1}=2.6573 \\
K_{D}=2.2913\end{array}$ & $\begin{array}{l}K_{P}=2.7727 \\
K_{1}=1.6615 \\
K_{D}=1.5962\end{array}$ & $\begin{array}{l}K_{P}=3.9448 \\
K_{1}=2.5180 \\
K_{D}=1.9787\end{array}$ & $\begin{array}{l}K_{P}=2.4043 \\
K_{1}=1.8551 \\
K_{D}=1.3273\end{array}$ & $\begin{array}{l}\mathrm{K}_{1}=0.971, \mathrm{~K}_{2}=0.957 \\
\mathrm{~T}_{\text {IPFC }}=0.9265, \mathrm{~K}_{\mathrm{RBF} 1}=0.9070 \\
\mathrm{~K}_{\mathrm{RBF2}}=0.9351, \mathrm{~T}_{\mathrm{RBF} 1}=0.997 \mathrm{~T}_{\mathrm{RBF2}}=0.9876\end{array}$ \\
\hline
\end{tabular}

techniques such as hFA-PS [21], IMC [4], ICA [20] and $\mathrm{ABC}$ [18] tuned PID controller. Figure 11, shows that oscillations and peak magnitudes are reduced with the proposed DE-AEFA-based controller, compared to others. This is because of the exploitation and exploration of capabilities possessed by the DE-

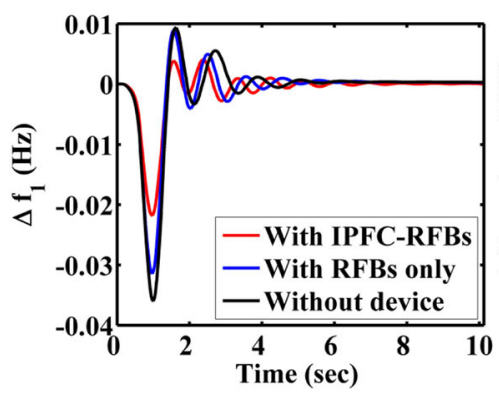

(a)

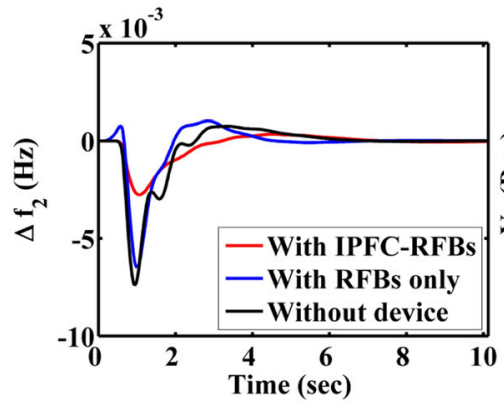

(c)

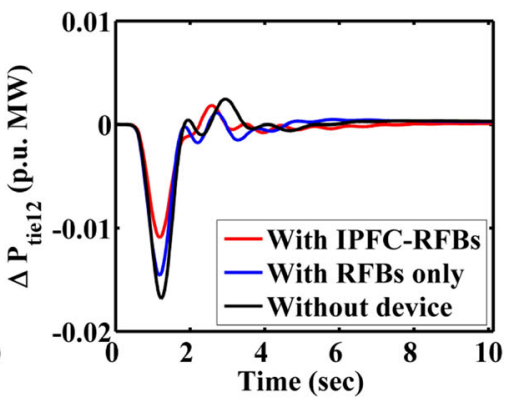

(b)

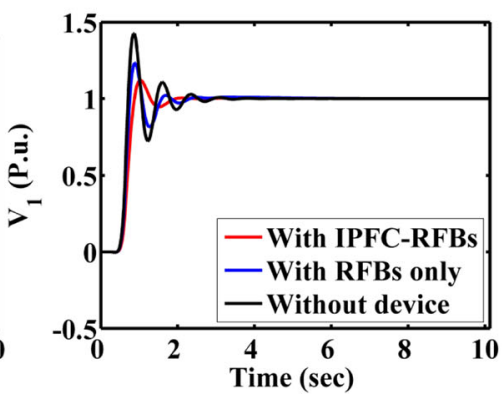

(d)

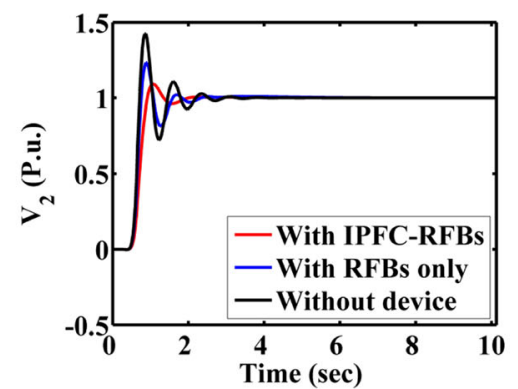

(e)

Fig. 16 Dynamic responses of LFC and AVR combined model considering CTDs, without and with IPFC and RFBs: a $\Delta f_{1} ; \mathbf{b} \Delta P_{\text {tie } 12 ;}$ c $\Delta \mathrm{f}_{2} ; \mathbf{d} \mathrm{V}_{1} ; \mathbf{e} \mathrm{V}_{2}$ 
Table 7 Numerical results for responses of combined LFC and AVR model with CTDs, with and without considering IPFC-RFBs

\begin{tabular}{|c|c|c|c|c|c|c|c|c|c|}
\hline \multirow[t]{2}{*}{ Parameters } & \multicolumn{3}{|c|}{ Without device } & \multicolumn{3}{|c|}{ With RFBs only } & \multicolumn{3}{|c|}{ With IPFC and RFBs only } \\
\hline & $\mathrm{T}_{\mathrm{S}}(\mathrm{Sec})$ & PU (-ve) & PO & $\mathrm{T}_{\mathrm{S}}(\mathrm{Sec})$ & PU (-ve) & $\mathrm{PO}$ & $\mathrm{T}_{\mathrm{S}}(\mathrm{Sec})$ & PU (-ve) & PO \\
\hline $\begin{array}{l}\Delta \mathrm{f}_{1} \\
* 10^{-3}\end{array}$ & 8.42 & 33.39 & 9.235 & 6.449 & 31.41 & 8.678 & 6.092 & 21.77 & 3.833 \\
\hline $\begin{array}{l}\Delta \mathrm{f}_{2} \\
* 10^{-3}\end{array}$ & 10.77 & 7.200 & 0.722 & 7.26 & 6.42 & 1.02 & 6.798 & 2.751 & 0.3439 \\
\hline $\begin{array}{l}\Delta \mathrm{P}_{\text {tie } 12} \\
* 10^{-3}\end{array}$ & 12.65 & 15.62 & 2.106 & 9.422 & 14.44 & 1.079 & 7.743 & 10.73 & 1.773 \\
\hline$V_{1}$ & 5.154 & 0.711 & 1.429 & 2.234 & 0.8171 & 1.233 & 1.557 & 0.955 & 1.127 \\
\hline$V_{2}$ & 5.020 & 0.745 & 1.428 & 2.108 & 0.8163 & 1.232 & 1.647 & 0.962 & 1.092 \\
\hline
\end{tabular}

AEFA searching mechanism. The optimum controller gains and the corresponding numerical results of system responses are tabulated in Table 3.

\subsection{Test system-3 dynamic analysis}

\subsubsection{Dynamic analysis of the LFC and AVR combined model without considering CTDs}

The conventional PID controller is incorporated in both LFC and AVR loops of test system-3 with hybrid generation sources as secondary controller without considering the CTDs. The parameters of the controllers are obtained separately with optimization algorithms of DE, AEFA and DE-AEFA algorithms subjected to the ISE function given in (6). The optimized controller parameters under different optimizations are noted in Table 5 and respective system dynamics are compared in Fig. 12 by subjecting area1 to $1 \%$ SLP. The characteristics of the responses of settling time (Ts), peak undershoot (PU) and overshoot (PO) are enumerated in Table 4. From Table 4 and Fig. 12, it reveals that the PU, PO and Ts of the responses under the proposed DE-AEFA-optimized PID controller are less than others and also the objective function value of DE-AEFA algorithm is improved by $52 \%$ and $43 \%$ compared to those of DE and AEFA algorithms, respectively.

\subsubsection{Dynamic analysis of LFC and AVR combined model considering CTDs}

Responses of the multi-area LFC and AVR combined model are analyzed by applying area-1 with $1 \%$ SLP while considering CTDs. The time delay parameter $(\mathrm{Td})$ is normally in the range of $0-1 \mathrm{~s}$ and a value of $0.25 \mathrm{~s}$ is used in this work. The controller parametric gain values are optimized with the proposed DE-AEFA algorithm to have satisfactory operation in regulating variations in frequency and tie-line power flow. System responses with the presented controller are also compared with those of DE and AEFA optimization algorithms. The controller optimal values are given in Table 5 and the accompanying dynamical system behaviors are compared in Fig. 13. The numerical results depicted in Fig. 13 are noted in Table 4 along with objective function values. The ISE index value of the presented DEAEFA approach is improved by $73 \%$ and $48 \%$ compared to those of DE and AEFA, respectively.

\subsubsection{System responses with and without considering AVR and CTDs comparison}

To investigate the impact of AVR coupling and CTDs on load frequency control, test system-3 is considered with and without AVR coupling and CTDs. In each case test system-3 is analyzed by applying area-1 with $1 \%$ SLP under the control of the proposed DE-AEFA optimized PID. The dynamic system responses are compared in Fig. 14. From Fig. 14, it is seen that CTDs and the AVR loop are exerting the most significant impact on LFC. The impact of AVR coupling on LFC can be seen through (1) while the effect of CTDs on controlling frequency, voltages and power flow via the tie-line is due to the lag in transmission and receiving of control signals among various units and load dispatch centers. By considering these CTDs the system dynamic responses are disturbed more than the case without considering CTDs. Thus, in order to investigate the system dynamics in a practical manner, CTDs need to be considered and the controller designed to withstand these deviations in

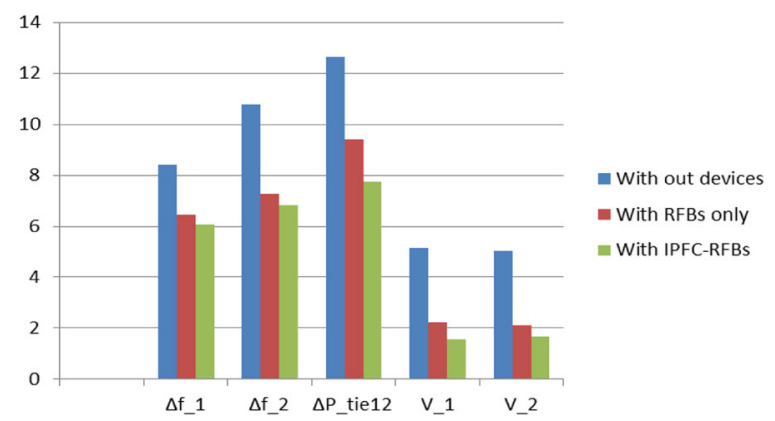

Fig. 17 Comparison of settling time of test system-3 responses considering CTDs, without IPFC and RFBs, with RFBs only and with IPFC-RFBs 


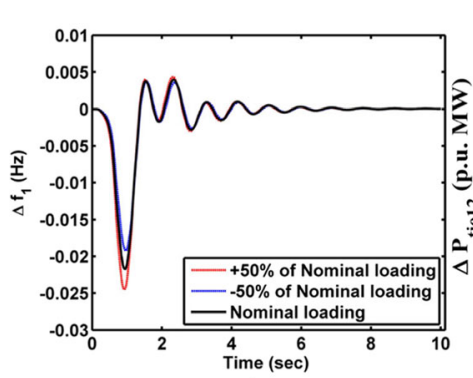

(a)

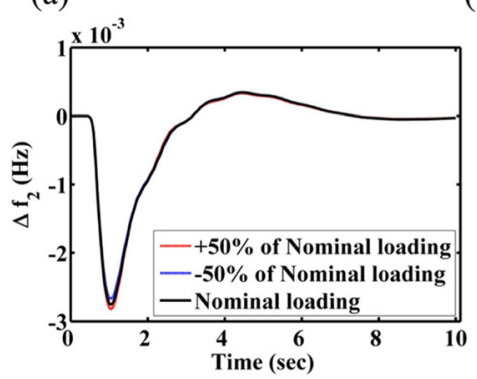

(c)

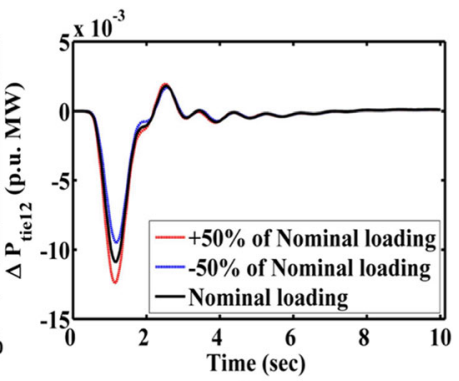

(b)

Fig. 18 Responses of LFC and AVR combined model with coordinated control strategy for $\pm 50 \%$ load variation from nominal load: a $\Delta \mathrm{f}_{1} ; \mathbf{b} \Delta \mathrm{P}_{\text {tie } 12} ; \mathbf{c} \Delta \mathrm{f}_{2}$

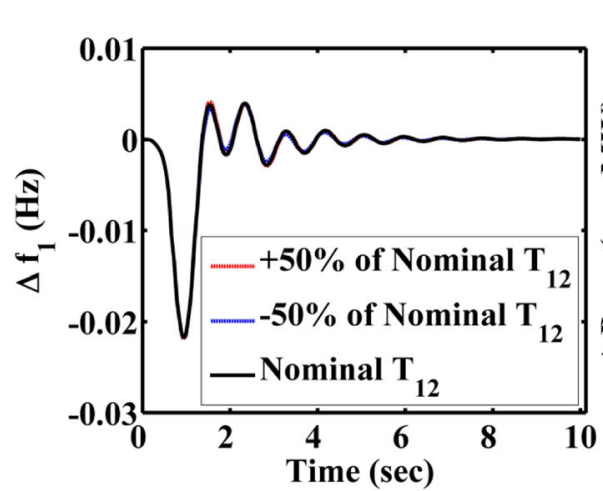

(a)

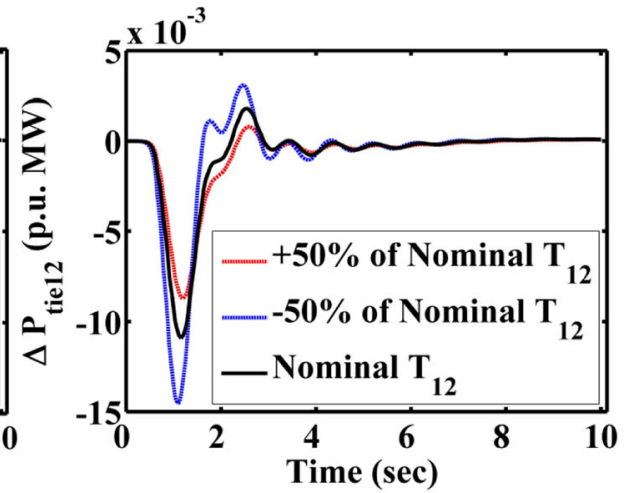

(b)

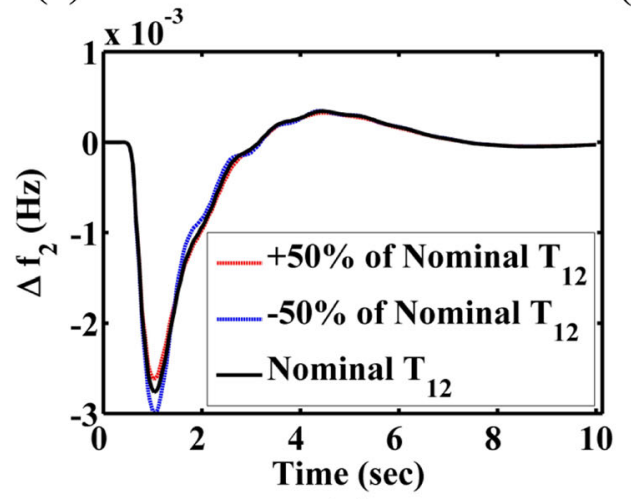

(c)

Fig. 19 Responses of LFC and AVR combined model with coordinated control strategy for $\pm 50 \%$ of tie-line synchronizing coefficient from nominal value: a $\Delta \mathrm{f}_{1} ; \mathbf{b} \Delta \mathrm{P}_{\text {tie12; }}$ c $\Delta \mathrm{f}_{2}$ 
system dynamics. Figure 15 compares the settling time of the dynamic responses in the LFC and AVR combined system with and without considering CTDs. It can be clearly seen that with CTDs responses are settled after a longer period. Hence, CTDs need to be considered to avoid performance deterioration.

\subsubsection{Coordinated control strategy of IPFC and RFBs in a combined model considering CTDs}

To further extenuate variations in frequency, terminal voltage and tie-line power, the combined model under investigation is installed with an IPFC in the tie-line and placing RFBs in both areas. Initially, RFBs are placed in both areas without an IPFC and the DE-AEFA tuned PID is used as a secondary controller with the system subjected to $1 \%$ SLP in area-1. The controller parameters and optimum gain and time constant parameters of RFBs are listed in Table 6, and the variations are compared in Fig. 16. IPFC is then connected in the tie-line while RFBs remain in areas 1 and 2 . The optimum parametric gain values of the controller are again shown in Table 6. Responses of the system are analyzed for the same disturbances and the respective dynamics are depicted in Fig. 16. The numerical values of the responses outlined in Fig. 16 are noted in Table 7. From Table 7 and Fig. 16, it is seen that the respective area frequency, voltage and tie-line deviations under load disturbances are greatly minimized and quickly reach the steady state values under the IPFC and RFBs coordinated control strategy along with the efficacy performance of the presented controller. Figure 17 compares the response settling time with and without considering IPFC and RFBs. It shows that the responses are settled smoothly through the proposed coordinated control mechanism.

\subsubsection{Sensitivity analysis}

To test the proposed coordinated regulating strategy robustness in mitigating variations in responses of the LFC and AVR combined model of test system-3, sensitivity analysis is performed. In the sensitivity analysis, parameters such as loading and tie-line synchronizing coefficient are varied at the level of $\pm 50 \%$ from nominal values. The dynamic behaviors of the system when it is subjected to a load variation of \pm $50 \%$ of nominal loading are shown in Fig. 18. The synchronizing tie-line coefficient value is then varied by $\pm 50 \%$ from its nominal value and the responses

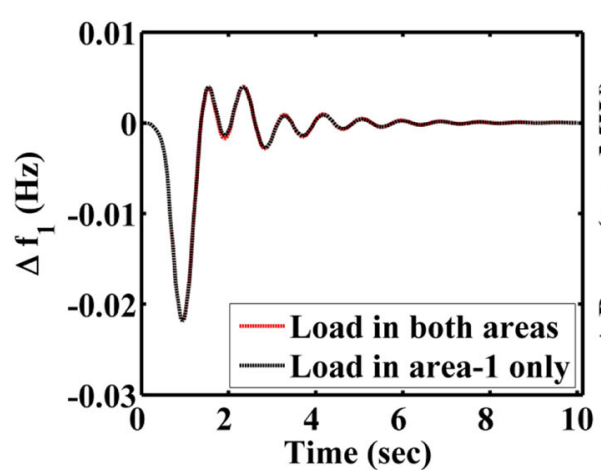

(a)

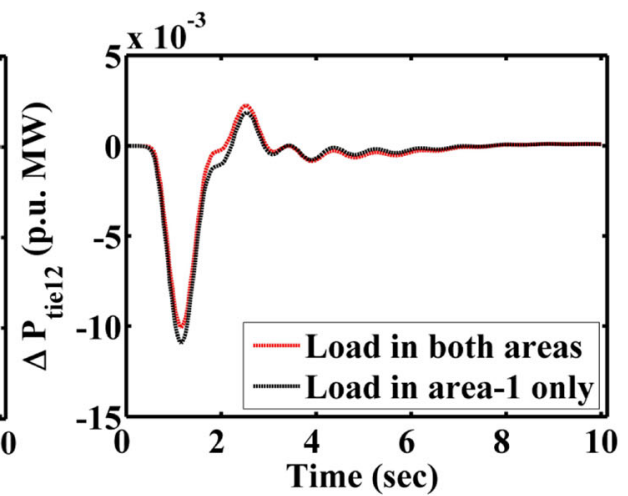

(b)

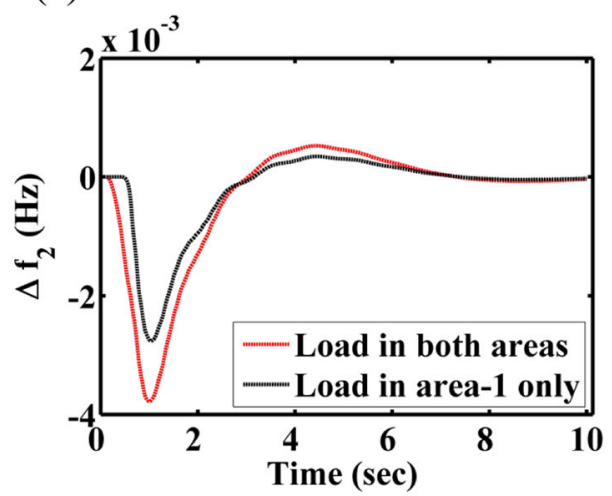

(c)

Fig. 20 Responses of the LFC and AVR combined model with coordinated control strategy for 1\%SLP in area-1 only and in both areas. a $\Delta \mathrm{f}_{1} \mathbf{b} \Delta \mathrm{P}_{\text {tie12 }} \mathbf{c} \Delta \mathrm{f}_{2}$ 
Table 8 Numerical results for test system-3 sensitivity analysis

\begin{tabular}{|c|c|c|c|c|}
\hline $\begin{array}{l}\text { Parameter } \\
\text { Change }\end{array}$ & Parameters & $\mathrm{T}_{\mathrm{S}}(\mathrm{Sec})$ & $\begin{array}{l}\text { PU } \\
\text { (-ve) }\end{array}$ & PO \\
\hline \multirow[t]{3}{*}{$\begin{array}{l}\text { Nominal } \\
\text { conditions }\end{array}$} & $\begin{array}{l}\Delta f_{1} \\
* 10^{-3}\end{array}$ & 6.092 & 21.77 & 3.833 \\
\hline & $\begin{array}{l}\Delta \mathrm{f}_{2} \\
* 10^{-3}\end{array}$ & 6.798 & 2.751 & 0.3439 \\
\hline & $\begin{array}{l}\Delta \mathrm{P}_{\text {tie } 12} \\
* 10^{-3}\end{array}$ & 7.743 & 10.73 & 1.773 \\
\hline \multirow{3}{*}{$\begin{array}{l}+50 \% \text { of } \\
\text { Nominal } \\
\text { loading }\end{array}$} & $\begin{array}{l}\Delta f_{1} \\
* 10^{-3}\end{array}$ & 6.192 & 24.13 & 4.354 \\
\hline & $\begin{array}{l}\Delta \mathrm{f}_{2} \\
* 10^{-3}\end{array}$ & 6.799 & 2.807 & 0.3439 \\
\hline & $\begin{array}{l}\Delta P_{\text {tie } 12} \\
* 10^{-3}\end{array}$ & 7.756 & 12.26 & 1.956 \\
\hline \multirow{3}{*}{$\begin{array}{l}-50 \% \text { of } \\
\text { Nominal } \\
\text { loading }\end{array}$} & $\begin{array}{l}\Delta f_{1} \\
* 10^{-3}\end{array}$ & 5.998 & 19.03 & 3.572 \\
\hline & $\begin{array}{l}\Delta f_{2} \\
* 10^{-3}\end{array}$ & 6.780 & 2.677 & 0.3439 \\
\hline & $\begin{array}{l}\Delta P_{\text {tie } 12} \\
* 10^{-3}\end{array}$ & 7.743 & 9.312 & 1.692 \\
\hline \multirow[t]{3}{*}{$+50 \%$ of $\mathrm{T}_{12}$} & $\begin{array}{l}\Delta f_{1} \\
* 10^{-3}\end{array}$ & 6.092 & 21.77 & 4.160 \\
\hline & $\begin{array}{l}\Delta f_{2} \\
* 10^{-3}\end{array}$ & 6.798 & 2.619 & 0.3243 \\
\hline & $\begin{array}{l}\Delta P_{\text {tie } 12} \\
* 10^{-3}\end{array}$ & 7.740 & 8.658 & 0.794 \\
\hline \multirow[t]{3}{*}{$-50 \%$ of $\mathrm{T}_{12}$} & $\begin{array}{l}\Delta f_{1} \\
* 10^{-3}\end{array}$ & 6.092 & 21.77 & 3.377 \\
\hline & $\begin{array}{l}\Delta f_{2} \\
* 10^{-3}\end{array}$ & 6.798 & 2.994 & 0.3439 \\
\hline & $\begin{array}{l}\Delta P_{\text {tie } 12} \\
* 10^{-3}\end{array}$ & 7.743 & 14.45 & 3.046 \\
\hline
\end{tabular}

obtained by applying area-1 with 1\% SLP are compared in Fig. 19. The system is also tested by applying load in both areas and the accompanying dynamical behavior is demonstrated in Fig. 20. The numerical results for the responses in sensitivity analysis are shown in Table 8. On examining Figs. 18, 19, 20, and Table 8 it is seen that the deviations are not significantly changed even in the case of large parametric variations. Thus it is concluded that the controller parameter gains are not required to be changed even when the system parameters such as synchronizing tie-line coefficient have large variations or when a wide range of disturbances is applied to the system. This means the controller gain parameters optimized with the proposed DE-AEFA algorithm along with coordinated control of IPFC and RFBs are robust. Finally, area-1 is applied with random loading to validate the robustness of the presented control strategy and the results are shown in Fig. 21.

\section{Conclusion}

In this paper, the impact of CTDs on frequency and voltage control of a multi-area LFC and AVR combined model of an interconnected system is studied. A conventional PID controller is used as secondary controller whose parameters are optimized with the DE-AEFA algorithm. The superiority of DE-AEFA is demonstrated by comparing it with other algorithms and standard optimizing benchmark functions. Furthermore, IPFC and

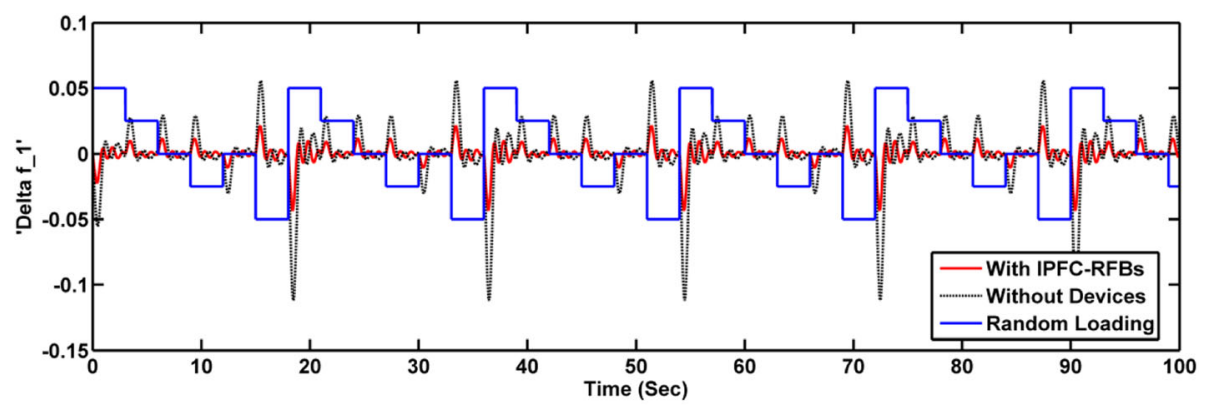

(a)

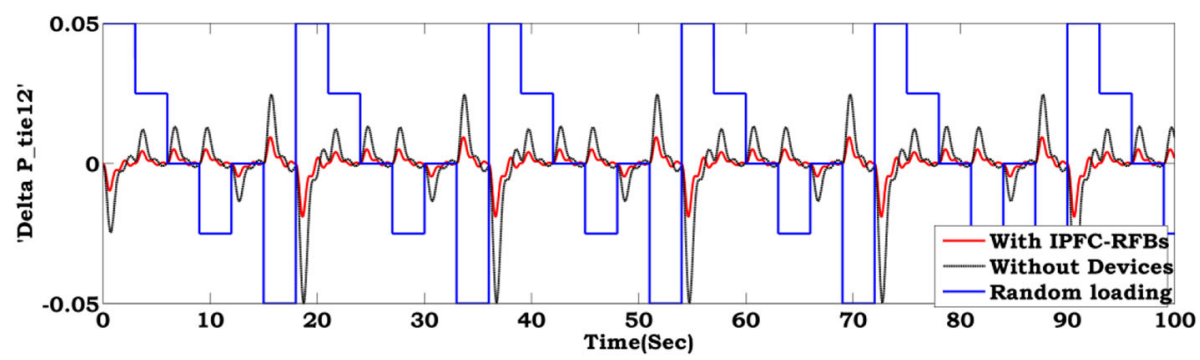

(b)

Fig. 21 Robustness of coordinated control strategy for test system-3: a $\Delta f_{1} ; \mathbf{b} \Delta P_{\text {tie12 }}$ 
RFBs are installed to mitigate system deviations under load disturbance. The investigation reveals that the coordinated performance of IPFC and RFBs can significantly diminish system deviations and quickly drive the dynamic responses to steady state under load disturbance. Sensitivity analysis reveals the robustness of the controller settings and time and gain constants of IPFC and RFBs optimized with DE-AEFA algorithm. Therefore, the same system can be implemented even when the system parameters and load are subjected to wide variations.

\section{Appendix}

\subsection{Parameters of the power system models}

Test system-1: $P_{r}$ (Rated power $)=2000 \mathrm{MW}, f($ System frequency $)=60 \mathrm{~Hz}, \quad B_{i} \quad$ (Area bias parameter $)=$ 0.425P.u.MW $/ \mathrm{Hz}, T t_{i}=0.3 \mathrm{~s}, T_{g i}=0.08 \mathrm{~s}, K_{P i}=120, T_{P i}=$ $20 \mathrm{~s}, T_{12}=0.545 \mathrm{~s}, R_{i}=2.4 \mathrm{~Hz} /$ p.u. $\mathrm{MW}$,

Test system-2: $P_{r}=2000 \mathrm{MW}, f=60 \mathrm{~Hz}, R_{1}=2 \mathrm{~Hz} / \mathrm{p}$.u. MW, $R_{2}=2.4 \mathrm{~Hz} /$ P.u.MW, $T_{t i}=0.3 \mathrm{~s}, K_{P i}=120, T_{P i}=20 \mathrm{~s}$, $T_{g i}=0.08 \mathrm{~s}, T_{12}=0.0707 \mathrm{puMW} / \mathrm{rad}, T_{R H i}=48.7 \mathrm{~s}, T_{G H i}=$ $0.513 \mathrm{~s}, T_{w i}=1 \mathrm{~s}, B_{i}=0.425$ P.u.MW $/ \mathrm{Hz}$.

Test system-3: $P_{r}$ (Rated power $)=2000 \mathrm{MW}, \mathrm{f}=($ fre quency) $=60 \mathrm{~Hz}, B_{i}=0.045$ P.u.MW $/ \mathrm{Hz}, H=5, D=$ $0.0145, T_{12}$ (Tie-line synchronizing time constant $)=$ $0.545 \mathrm{~s}, \quad K_{P S}=1 / D, \quad T_{P S}=2 H / D f$, Thermal plant: Kre (steam reheat turbine constant) $=0.3, \tau_{g r}, \tau_{r e}, \tau_{T r}$ (governor, reheater, turbine time constants) $=0.08 \mathrm{~s}, 10 \mathrm{~s}, 0.3 \mathrm{~s}$, $R_{t}, R_{h}, R_{g}=2.4 \mathrm{~Hz} /$ P.u. Hydro plant: $\tau_{h}$ (hydro governor time constant) $=0.3 \mathrm{~s}, \tau_{r s}$ (reset time) $=5 \mathrm{~s}, \tau_{w}$ (starting time of water into penstock) $=0.025 \mathrm{~s}$, Gas Plant: $\mathrm{X}=$ (governor lead time) $=0.6 \mathrm{~s}, \mathrm{Y}=($ governor lag time $)=1 \mathrm{~s}$, $\mathrm{a}, \mathrm{b}, \mathrm{c}=$ (valve position constants) $=1 \mathrm{~s}, 0.05 \mathrm{~s}, 1 \mathrm{~s}, \quad \tau_{C R}$ (Time delay of combustion reaction) $=0.01 \mathrm{~s}, \tau_{F}=0.23 \mathrm{~s}$, $\tau_{C D}=0.2 \mathrm{~s}$. Wind plant: $\tau_{W 1}, \tau_{W 2}=0.6 \mathrm{~s}, 0.041 \mathrm{~s}, K_{w 1}, K_{w 2}$ (wind plant gain constants) $=1.25,1.4$. Diesel plant: $K_{D}=$ $16.5, \tau_{d 1}, \tau_{d 2}, \tau_{d 3} \tau_{d 4}$ (time constants of diesel engine) $=$ $1 \mathrm{~s}, 2 \mathrm{~s}, 0.025 \mathrm{~s}, 3 \mathrm{~s}$. Solar PV: $\tau_{P V}=($ solar PV time constant $)=1.8 \mathrm{~s} . \mathrm{K}_{\mathrm{RFBs}}=1, \mathrm{~T}_{\mathrm{RFBS}}=0.9, \mathrm{~T}_{\mathrm{IPFC}}=0.0450$, AVR: (Exciter constants) $K_{E}=1, \tau_{E}=0.4 \mathrm{~s}, K_{G}=0.8, \tau_{G}=1.4 \mathrm{~s}$, (amplifier constants) $K_{A}=10, \tau_{\mathrm{A}}=0.1 \mathrm{~s}$, (sensor constants) $\mathrm{K}_{\mathrm{S}}=1, \mathrm{\tau}_{\mathrm{S}}=0.05 \mathrm{~s}$, Ps $=1.5, \mathrm{~K}_{1}=0.2, \mathrm{~K}_{2}=-0.1, \mathrm{~K}_{3}=$ $0.5, \mathrm{~K}_{4}=1.4$.

\section{Abbreviations}

AVR: Automatic voltage regulator; LFC: Load frequency control; CTDs: Communication time delays; PMUs: Phase measuring units; GRC: Generation rate constraints; ISE: Integral square error; DE: Differential evolution; AEFA: Artificial electric field algorithm; RFBs: Redox flow batteries; IPFC: Interline power flow controller; ESDs: Energy storage devices; PU: Peak undershoot; $T_{s}$ : Settling time; PO: Peak overshoot

\section{Authors' contributions}

Developed the two-area combined LFC and AVR of interconnected power system with hybrid generating sources considering communication time delays (CTDs). No literature is available on analysis of combined LFC and AVR of interconnected system with CTDs. Presented a methodology to damp out the frequency and voltage deviations of an interconnected system simultaneously. DE-AEFA algorithm is proposed to optimized PID controller is presented for combined LFC and AVR model. The superiority of proposed DEAEFA algorithm is demonstrated by tested on standard benchmark functions. The performance of DE-AEFA algorithm is validated with other optimization algorithms reported in literature by conducting investigations on widely used test systems. Effect of coordinated performance of IPFC and RFBs in combined effect is investigated. Sensitivity analysis is performed to demonstrate the robustness of proposed coordinated control strategy. The author(s) read and approved the final manuscript.

Funding

Not applicable.

\section{Availability of data and materials}

The data used for developing SIMULINK models is given in Appendix. No other data is available.

\section{Competing interests}

Not applicable.

\section{Author details}

${ }^{1}$ EEE Department, Acharya Nagarjuna University, Guntur, A.P., India. ${ }^{2}$ EEE Department, RVR\&JC College of Engineering, Guntur, A.P., India.

Received: 16 April 2020 Accepted: 29 January 2021

Published online: 03 March 2021

\section{References}

1. Fosha, E., \& Elgerd, O. (1970). The megawatt-frequency control problem: A new approach via optimal control theory. IEEE Transactions on Power Apparatus and Systems, 89(4), 563-577.

2. Guha, D., Roy, P. K., \& Banerjee, S. (2016). Load frequency control of interconnected power system using grey wolf optimization. Swarm and Evolutionary Computation, 27, 97-115.

3. Kouba, N. E. L. Y., Meena, M., Hasni, M., \& Boudour, M. (2017). A new optimal load frequency control based on hybrid genetic algorithm and particle swarm optimization. International Journal on Electrical Engineering and Informatics, 9(3), 418-440.

4. Jay, S., Kalyan, C., \& Vishwakarma, C. B. (2018). Two degree of freedom integral model control - PID design for LFC of power systems via logarithmic approximations. ISA Transactions, 72, 185-196.

5. Bheem, S., Deepak, K., \& Paulson, S. (2019). Dual loop IMC structure for load frequency control issue of multi-area multi-sources power systems. Electrical Power and Energy Systems, 112, 476-494.

6. Arya, Y. (2018). Improvement in automatic generation control of two-area electric power systems via a new fuzzy aided optimal PIDN-FOI controller. ISA Transactions, 80, 475-490.

7. Morsali, J., Zare, K., \& Hagh, M. (2018). Comparative performance evaluation of fractional order controllers in LFC of two-area diverse-unit power system with considering GDB and GRC effects. Journal of Electrical Systems and Information Technology, 5(3), 708-722.

8. Chandrakala, K. R. M. V., \& Balamurugan, S. (2018). Adaptive Neuro-fuzzy scheduled load frequency controller for multi-source multi area system interconnected via parallel AC-DC links. International Journal on Electrical Engineering and Informatics, 10(3), 479-490.

9. Rakhshani, E., \& Rouzbehi, K. S. (2009). A new combined model for simulation of mutual effects between LFC and AVR loops. In Asia-Pacific Power and Energy Engineering Conference, (pp. 1-5). Wuhan: IEEE. https://doi. org/10.1109/APPEEC.2009.4918066.

10. Gupta, A., Chauhan, A., \& Khanna, R. (2014). Design of AVR and ALFC for single area power system including damping control. In Recent Advances in Engineering and Computational Sciences (RAECS), (pp. 1-5). Chandigarh: IEEE. https://doi.org/10.1109/RAECS.2014.6799653.

11. Chandrakala, K. R. M. V., \& Balamurugan, S. (2016). Simulated annealing based optimal frequency and terminal voltage control of 
multi source multi area system. Electrical Power and Energy Systems, $78,823-829$.

12. Rajbongshi, R., \& Saikia, L. C. (2017). Combined control of voltage and frequency of multi-area multisource system incorporating solar thermal power plant using LSA optimized classical controllers. IET Generation Transmission and Distribution, 11(10), 2489-2498.

13. Madasu, D. S., Kumar, M. L. S. S., \& Singh, A. K. (2018). A flower pollination algorithm based automatic generation control of interconnected power system. Ain Shams Engineering Journal, 9(4), 1215-1224.

14. Kouba, N. E. L. Y., Meena, M., Hasni, M., \& Boudour, M. (2018). A novel optimal combined fuzzy PID controller employing dragonfly algorithm for solving automatic generation control problem. Electric Power Components \& Systems, 46(19-20), 2054-2070.

15. Sahoo, B. P., \& Panda, S. (2018). Improved grey wolf optimization technique for fuzzy aided PID controller design for power system frequency control. Sustainable Energy, Grids and Networks, 16, 278-299.

16. Dillip, K., Sahu, R. K., Tulasichandra, S. G., \& Panda, S. (2019). Automatic generation control of power system in deregulated environment using hybrid TLBO and pattern search technique. Ain Shams Engineering Journal. https://doi.org/10.1016/j.asej.2019.10.012.

17. Panda, S., \& Mohanty, B. (2013). Hybrid BFOA-PSO algorithm for automatic generation control of linear and non-linear interconnected power systems. Applied Soft Computing Journal, 13(12), 4718-4730.

18. Gozde, H., Taplamacioglu, M. C., \& Kocaarslan, I. (2012). Comparative performance analysis of artificial bee colony algorithm in automatic generation control for interconnected reheat thermal power system. Electrical Power and Energy Systems, 42(1), 167-178.

19. Guha, D., Roy, P. K., \& Banerjee, S. (2018). Application of backtracing search algorithm in load frequency control of multi-area interconnected power system. Ain Shams Engineering Journal, 9(2), 257-276.

20. Shabani, H., Vahidi, B., \& Majid.E. (2012). A robust PID controller based on imperialist competitive algorithm for load-frequency control of power systems. ISA Transactions, 52(1), 88-95.

21. Sahu, R. K., Panda, S., \& Padhan, S. (2015). A hybrid firefly algorithm and pattern search technique for automatic generation control of multi area power systems. Electrical Power and Energy Systems, 64, 9-23.

22. Saadat, H. (1999). Power system analysis. USA: McGraw-Hill.

23. Vijay, P. S., Nand, K., \& Paulson.S. (2015). Communication time delay estimation for load frequency control in two-area power system. Ad Hoc Networks, 41(1), 69-85.

24. Stom, R., \& price, K. (1997). Differential evolution- a simple and efficient heuristic for global optimization over continuous spaces. Journal of Global Optimization, 11(4), 341-359.

25. Vesterstrom, J., \& Thomson, R. (2004). A comparative study of differential evolution, particle swarm optimization, and evolutionary algorithms on numerical benchmark problems. In Proceedings of 2004 IEEE congress on evolutionary computation, (pp. 1980-1987)

26. Anita., \& Yadav, A. (2019). Artificial electric field algorithm for global optimization. Swarm and Evolutionary Computation Base Data, 48, 93-108.

27. Tasnin, W., \& Saikia, L. C. (2018). Comparative performance of different energy storage devices in AGC of multi-source system including geothermal power plant. Journal of Renewable and Sustainable Energy, 10(024101), 1-15.

\section{Submit your manuscript to a SpringerOpen ${ }^{\circ}$ journal and benefit from:}

- Convenient online submission

- Rigorous peer review

- Open access: articles freely available online

- High visibility within the field

- Retaining the copyright to your article

Submit your next manuscript at $\boldsymbol{\nabla}$ springeropen.com 